OPEN ACCESS

Edited by:

Brice Rotureau,

Institut Pasteur, France

Reviewed by:

Catherine Ayn Brissette, University of North Dakota

United States

Melissa Jo Caimano, University of Connecticut Health

Center, United States

*Correspondence:

Sarah I. Bonnet

sarah.bonnet@vet-alfort.fr

Received: 29 March 2017 Accepted: 04 May 2017 Published: 22 May 2017

Citation:

Blisnick AA, Foulon T and Bonnet SI (2017) Serine Protease Inhibitors in

Ticks: An Overview of Their Role in Tick Biology and Tick-Borne Pathogen Transmission

Front. Cell. Infect. Microbiol. 7:199 doi: 10.3389/fcimb.2017.00199

\section{Serine Protease Inhibitors in Ticks: An Overview of Their Role in Tick Biology and Tick-Borne Pathogen Transmission}

\author{
Adrien A. Blisnick ${ }^{1}$, Thierry Foulon ${ }^{2}$ and Sarah I. Bonnet ${ }^{1 *}$ \\ 1 UMR BIPAR INRA-ENVA-ANSES, Maisons-Alfort, France, ${ }^{2}$ Centre National de la Recherche Scientifique, Institut de Biologie \\ Paris-Seine, Biogenèse des Signaux Peptidiques, Sorbonne Universités, UPMC Univ. Paris 06, Paris, France
}

New tick and tick-borne pathogen control approaches that are both environmentally sustainable and which provide broad protection are urgently needed. Their development, however, will rely on a greater understanding of tick biology, tick-pathogen, and tick-host interactions. The recent advances in new generation technologies to study genomes, transcriptomes, and proteomes has resulted in a plethora of tick biomacromolecular studies. Among these, many enzyme inhibitors have been described, notably serine protease inhibitors (SPIs), whose importance in various tick biological processes is only just beginning to be fully appreciated. Among the multiple active substances secreted during tick feeding, SPIs have been shown to be directly involved in regulation of inflammation, blood clotting, wound healing, vasoconstriction and the modulation of host defense mechanisms. In light of these activities, several SPIs were examined and were experimentally confirmed to facilitate tick pathogen transmission. In addition, to prevent coagulation of the ingested blood meal within the tick alimentary canal, SPIs are also involved in blood digestion and nutrient extraction from the meal. The presence of SPIs in tick hemocytes and their involvement in tick innate immune defenses have also been demonstrated, as well as their implication in hemolymph coagulation and egg development. Considering the involvement of SPIs in multiple crucial aspects of tick-host-pathogen interactions, as well as in various aspects of the tick parasitic lifestyle, these molecules represent highly suitable and attractive targets for the development of effective tick control strategies. Here we review the current knowledge regarding this class of inhibitors in tick biology and tick-borne pathogen transmission, and their potential as targets for future tick control trials.

Keywords: ticks, tick serine protease inhibitors, tick-borne pathogens, tick-host interactions, immune responses

\section{INTRODUCTION}

Ticks are among the most common and important vectors of both human and animal pathogens worldwide including some parasites, bacteria and viruses (Dantas-Torres et al., 2012). These obligate hematophagous arthropods are divided into two main families; soft and hard ticks. Tick developmental stages include larval, nymphal and adult forms, all of which-for most species-require blood meals to complete development and enable reproduction. Compared to 
other hematophagous arthropods, hard -or Ixodidae- tick feeding is a slow and complex process, taking several days until repletion, and thus necessitates extended control over the vertebrate host's immune response. Whereas the soft-or Argasidae-ticks usually complete a blood meal in less than $1 \mathrm{~h}$ (Sonenshine and Anderson, 2014). During this feeding process, all ticks inject saliva and absorb blood alternately. Blood cells are lysed in the midgut lumen and, in contrast to other hematophagous arthropods, further digestion of proteins and other blood molecules occurs intracellularly, taking place within midgut epithelial cells.

Current tick control strategies essentially rely on the use of chemical acaricides and repellents. Their widespread deployment however, has a profound environmental impact (Rajput et al., 2006; De Meneghi et al., 2016), and has led to the emergence of resistance in multiple tick species (Rosario-Cruz et al., 2009; Adakal et al., 2013). New environmentally sustainable approaches providing broader protection against current and future tickborne pathogens (TBP) are thus urgently needed. To investigate new candidate pathways to fight the spread of these pathogens, a complete understanding of tick biology, tick-pathogen and tick-host interactions is essential. Since the beginning of the twenty first century the continual development of cutting-edge high-throughput methods has enabled the study of genomes, transcriptomes, and proteomes, thus facilitating many diverse biomolecular studies (Metzker, 2010). These tools have been essential in the discovery of specific tick biological gene products. The most studied tick species have been those that present significant human and/or livestock disease risk in the northern hemisphere: Ixodes scapularis in the USA (deer; black-legged tick); Ixodes persulcatus in Asia and Eastern Europe (Taiga tick); and Ixodes ricinus in western and central Europe (sheep tick). Additionally, the Rhipicephalus (Boophilus) microplus cattle tick that causes massive damage in Australia, Africa, Central America, and Asia has also been intensively studied.

Most studies have investigated specific tick organ transcriptomes under a variety of conditions, especially tick salivary glands (SGs) (Santos et al., 2004; Francischetti et al., 2005b; Ribeiro et al., 2006; Garcia et al., 2014; Liu et al., 2014) or midgut (Anderson et al., 2008; Chmelar et al., 2016), occasionally eggs or ovaries (Santos et al., 2004), and less frequently hemocytes (Santos et al., 2004; Kotsyfakis et al., 2015), body fat

\footnotetext{
Abbreviations: $\alpha 2 \mathrm{M}$, alpha 2-macroglobulin; APC, antigen presenting cells; aPTT, activated partial thromboplastin time; BPTI, bovine pancreatic trypsin inhibitor; BSAP, BaSO4 $4^{-}$adsorbing protein; CAMs, chorioalantoic membranes; Efh, EF hand; FCT, fibrinogen clotting time; FRP, follistatin-related-protein; HBE, heparin binding exosite; HMWK, high molecular weight kininogen; hNE, human neutrophil elastase; hTFPI, human tissue factor pathway inhibitor; HuPK, human prekalikrein; HUVEC, human umbilical vein endothelial cells; LICI, limulus intracellular coagulation inhibitor; MA, methyl amine; PAR, proteinase activated receptor; PARP, poly (ADP-r-ribose) polymerase; PDGF, platelet-derived growth factor; PECAM-1, platelet-endothelial cell adhesion molecule-1; PPE, porcine pancreatic elastase; PT, prothrombin time; RCL, reactive center loop; RCT, recalcification time assay; RNAi, RNA interference; SGs, salivary glands; STAT 3, signal transducer and activator of transcription 3; STI, soybean trypsin inhibitor; TBP, tick-borne pathogens; TF, tissue factor; TGF-alpha, tissue growth factor alpha; TIL, trypsin inhibitor-like domain; tSPI, tick serine protease inhibitor; TT, thrombin clotting time; VEGF, vascular endothelial growth factor.
}

or synganglia (Bissinger et al., 2011; Egekwu et al., 2014). Several comprehensive protein catalogs describing protein diversity in various tick fluids such as saliva (Madden et al., 2004; Cotté et al., 2014; Radulovic et al., 2014; Tirloni et al., 2014a, 2015) or hemolymph (Gudderra et al., 2002; Stopforth et al., 2010), as well as in midgut during feeding (Schwarz et al., 2014; Oleaga et al., 2015), have been compiled, vital to understanding mechanisms implicated in different biological processes such as tick feeding or tick immunity.

Several studies also reported that TBP can influence gene and protein expression in tick, highlighting evidence of molecular interaction between pathogens and the vector (review in Liu and Bonnet, 2014). These studies focused on specific organs including SGs, midgut, ovaries, or on the whole tick during infections with several different pathogens, and reported differential expression of tick's genes links to pathogen transmission. TBP are imbibed by tick when feeding on a pathogen-infected vertebrate host and, once ingested, they directly or not -depending of the pathogenescape the midgut and invade the SGs and the ovaries for vertically transmitted pathogens (see Liu and Bonnet, 2014). Then, for most TBP, transmission to a new host occurs via the saliva during blood feeding. During both their transmission and development into the vector, TBP undergo developmental transitions and migrations and suffer population losses, to which tick factors surely contribute. In addition, during the prolonged tick-host attachment period, many proteins injected into the host via tick saliva dampen host defenses, thereby creating a favorable environment for survival and propagation of TBP (Brossard and Wikel, 2004; Nuttall and Labuda, 2004; Ramamoorthi et al., 2005; Wikel, 2013).

Many enzyme activity inhibitors were described among the transcripts or proteins detected in these studies, including multiple protease inhibitors often belonging to serine protease inhibitor families. These inhibitors can vary in molecular weight from less than $10 \mathrm{kDa}$ to almost $100 \mathrm{kDa}$, and can reversibly or irreversibly inhibit their targets via family-specific domains. Their global tissue expression suggests involvement in various important tick biological pathways, including innate immunity, hemolymph clotting formation, blood uptake, digestion, as well as oviposition and egg laying. In addition, tick serine protease inhibitors (tSPIs) also modulate vertebrate host responses during biting, act on hemostasis, immune responses, or angiogenesis. Their implications in these various processes suggest that tSPIs can indirectly influence tick pathogen transmission, and indeed some have been directly experimentally linked with TBP transmission. The aim of the present review is to summarize current knowledge concerning these tSPIs (detailed in Table 1), in order to highlight their role in tick biology, TBP transmission, and to identify putative targets which could contribute to effective tick and TBP control strategies.

\section{THE SERINE PROTEASE INHIBITOR FAMILY}

Four groups of serine protease inhibitors have been identified in plants and animals, and can be classified into two main 
TABLE 1 | Tick serine protease inhibitors implicated in both tick biology/physiology and modulation of vertebrate host responses to tick bite, classified according to their inhibitor group (Serpin, Macroglobuline, Kunitz, Kazal), and the corresponding tick species.

\begin{tabular}{|c|c|c|c|c|c|}
\hline Inhibitor name & $\begin{array}{c}\text { Molecular } \\
\text { weight (kDa) }\end{array}$ & Inhibitor type & Tick species & Action & References \\
\hline \multicolumn{6}{|c|}{ TICK IMMUNE SYSTEM FACTORS } \\
\hline TAM & 420 & $\alpha 2 \mathrm{M}$ & O. moubata & Tick immune defense & Kopacek et al., 2000 \\
\hline IrAM & 440 & $\alpha 2 \mathrm{M}$ & 1. ricinus & Antimicrobial activity & Buresova et al., 2009 \\
\hline $\mathrm{BmCl}$ & 6.5 & Kunitz & R. (B.) microplus & Antimicrobial activity & Lima et al., 2010 \\
\hline DvKPI & 62 & Kunitz & D. variabilis & Antimicrobial activity & Ceraul et al., 2008 \\
\hline Ixodidin & 7.1 & $\begin{array}{l}\text { Trypsin Inhibitor } \\
\text { Like (TIL) }\end{array}$ & R. (B.) microplus & Antimicrobial activity & Fogaça et al., 2006 \\
\hline BmSI 6-7 & $7.4,7.3$ & $\begin{array}{l}\text { Trypsin Inhibitor } \\
\text { Like (TIL) }\end{array}$ & R. (B.) microplus & $\begin{array}{l}\text { Antimicrobial activity and tissue } \\
\text { preservation }\end{array}$ & Sasaki et al., 2008 \\
\hline BmTI-A & 13.5 & Kunitz & R. (B.) microplus & Probable antimicrobial activity & Tanaka et al., 1999 \\
\hline \multicolumn{6}{|c|}{ HEMOLYMPH CLOTTING FACTORS } \\
\hline HLS 2 & 44 & Serpin & H. longicornis & Hemolymph clot formation & Imamura et al., 2005 \\
\hline HLSG-1 & 37.7 & Serpin & H. longicornis & Hemolymph clot formation & Mulenga et al., 2001 \\
\hline RAS 3-4 & $43.2,53.9$ & Serpin & R. appendiculatus & Hemolymph clot formation & Mulenga et al., 2003b \\
\hline \multicolumn{6}{|c|}{ BLOOD UPTAKE AND DIGESTION MODULATORS } \\
\hline HLSG-2 & 31.2 & Serpin & H. longicornis & Probable blood digestion helper & Mulenga et al., 2001 \\
\hline HIMKI & 12 & Kunitz & H. longicornis & Probable blood digestion helper & Miyoshi et al., 2010 \\
\hline HLS-1 & 41 & Serpin & H. longicornis & $\begin{array}{l}\text { Probable blood uptake and digestion } \\
\text { helper }\end{array}$ & Sugino et al., 2003 \\
\hline HIChl & 6.7 & Kunitz & H. longicornis & Probable blood digestion helper & Alim et al., 2012 \\
\hline RAMSP 1-3 & $32.3,51.2,49.5$ & - & R. appendiculatus & Probable blood digestion helper & Mulenga et al., 2003a \\
\hline RAS-1 and -2 & $41.9,42.7$ & Serpin & R. appendiculatus & Probable blood digestion helper & Mulenga et al., 2003b \\
\hline AAS19 & 43 & Serpin & A. americanum & Probable blood digestion helper & Kim et al., 2015 \\
\hline $\begin{array}{l}\text { RMS-3 }-6-9-13-15 \\
-16-17-21-22\end{array}$ & $40-55$ & Serpin & R. (B.) microplus & Probable blood digestion helper & $\begin{array}{l}\text { Tirloni et al., 2014a,b; } \\
\text { Rodriguez-Valle et al., } 2015\end{array}$ \\
\hline $\mathrm{BmTl}-\mathrm{A}$ & 13.5 & Kunitz & R. (B.) microplus & Probable blood digestion helper & Sasaki et al., 2004 \\
\hline BmTI-D & 1.6 & Kunitz & R. (B.) microplus & Probable blood digestion helper & Sasaki et al., 2004 \\
\hline AamS6 & 42 & Serpin & A. americanum & Probable blood digestion helper & $\begin{array}{l}\text { Chalaire et al., 2011; } \\
\text { Mulenga et al., } 2013\end{array}$ \\
\hline Ixophilin & 54.4 & Kunitz & I. scapularis & Probable blood digestion helper & Narasimhan et al., 2013 \\
\hline \multicolumn{6}{|c|}{ TICK DEVELOPMENT, OVIPOSITION, EGG LAYING, AND MOLTING FACTORS } \\
\hline BmTls & $6.2-18.4$ & Kunitz & R. (B.) microplus & Tick egg production and development & Tanaka et al., 1999 \\
\hline RMS-3 & 40 & Serpin & R. (B.) microplus & Tick reproduction egg production & Rodriguez-Valle et al., 2012 \\
\hline RMS-6 & 40 & Serpin & R. (B.) microplus & Probable role in embryogenesis & Rodriguez-Valle et al., 2012 \\
\hline RMS-19 & 40.7 & Serpin & R. (B.) microplus & Role in tick development & Rodriguez-Valle et al., 2012 \\
\hline RMS-20 & 31.1 & Serpin & R. (B.) microplus & Role in tick development & Rodriguez-Valle et al., 2012 \\
\hline RMS-21 & 12.5 & Serpin & R. (B.) microplus & Probable role in embryogenesis & Rodriguez-Valle et al., 2012 \\
\hline RMS-22 & 10.7 & Serpin & R. (B.) microplus & Probable role in embryogenesis & Rodriguez-Valle et al., 2012 \\
\hline RmKK & 16.7 & kunitz & R. (B.) microplus & $\begin{array}{l}\text { Probable protection of undesired egg } \\
\text { proteolysis }\end{array}$ & Abreu et al., 2014 \\
\hline BmTl-6 & 33.8 & kunitz & R. (B.) microplus & $\begin{array}{l}\text { Regulation of egg production and } \\
\text { proteases in eggs and larvae }\end{array}$ & $\begin{array}{l}\text { Andreotti et al., 2001; } \\
\text { Sasaki et al., 2004; Sasaki } \\
\text { and Tanaka, } 2008\end{array}$ \\
\hline RsTls & $8-18$ & kunitz & R. (B.) microplus & $\begin{array}{l}\text { Regulation of egg production and } \\
\text { proteases in eggs and larvae }\end{array}$ & $\begin{array}{l}\text { Sant'Anna Azzolini et al., } \\
2003\end{array}$ \\
\hline Tick FRP & 32 & Kazal & H. longicornis & Role in tick oviposition & Zhou et al., 2006 \\
\hline AAS19 & 43 & Serpin & A. americanum & Role in tick oviposition & Kim et al., 2016 \\
\hline \multicolumn{6}{|c|}{ HOST-EXTRINSIC PATHWAY TICK INHIBITORS } \\
\hline Ixolaris & 15.7 & Kunitz & I. scapularis & Blocks FVIla/TF complex activity & Francischetti et al., 2002 \\
\hline Penthalaris & 35 & Kunitz & I. scapularis & Block FVIla/TF complex activity & Francischetti et al., 2004 \\
\hline
\end{tabular}


TABLE 1 | Continued

\begin{tabular}{|c|c|c|c|c|c|}
\hline Inhibitor name & $\begin{array}{c}\text { Molecular } \\
\text { weight (kDa) }\end{array}$ & Inhibitor type & Tick species & Action & References \\
\hline BSAP1 & 9.3 & - & O. savignyi & Targets tissue factor (TF) & Ehebauer et al., 2002 \\
\hline \multicolumn{6}{|c|}{ HOST-INTRINSIC PATHWAY TICK INHIBITORS } \\
\hline IrCPI & 9.7 & Kunitz & I. ricinus & $\begin{array}{l}\text { Blocks FXII, FXI, and kallikrein } \\
\text { activation }\end{array}$ & Decrem et al., 2009 \\
\hline Rhipilin-2 & 22 & Kunitz & R. (B.) microplus & Affects APTT test clotting time & Cao et al., 2013 \\
\hline Haemaphysalin & - & Kunitz & H. longicornis & $\begin{array}{l}\text { Blocks kallikrein-kinin system } \\
\text { activation }\end{array}$ & Kato et al., 2005a,b \\
\hline DvKPI & 62 & Kunitz & D. variabilis & Affects APTT test clotting time & Ceraul et al., 2008 \\
\hline \multicolumn{6}{|c|}{ HOST-FX(a) FACTOR TICK INHIBITORS } \\
\hline & 15 & - & H. dromaderii & Blocks FXa activity & Ibrahim et al., 2001b \\
\hline & 65 & Serpin & R. appendiculatus & Blocks FXa activity & Limo et al., 1991 \\
\hline AAS19 & 43 & Serpin & A. americanum & Blocks FXa and plasmin action & Kim et al., 2015, 2016 \\
\hline Amblyomin-X & 13.5 & Kunitz & A. cajennense & $\begin{array}{l}\text { Blocks FVlla/TF complex activity and } \\
\text { prothombin conversion }\end{array}$ & $\begin{array}{l}\text { Batista et al., 2010; Branco } \\
\text { et al., } 2016\end{array}$ \\
\hline \multicolumn{6}{|c|}{ HOST-THROMBIN INHIBITING TICK FACTOR } \\
\hline $\mathrm{BmAP}$ & 60 & - & R. (B.) microplus & Thrombin inhibitor & Horn et al., 2000 \\
\hline Microphilin & 1.7 & - & R. (B.) microplus & Thrombin inhibitor & Ciprandi et al., 2006 \\
\hline BmGTI & 26 & - & R. (B.) microplus & Thrombin inhibitor & Ricci et al., 2007 \\
\hline RMS 15 & 48 & & R. (B.) microplus & Thrombin inhibitor & $\begin{array}{l}\text { Rodriguez-Valle et al., 2015; } \\
\text { Xu et al., } 2016\end{array}$ \\
\hline HLS2 & 44 & Serpin & H. longicornis & Weak thrombin inhibitor & Imamura et al., 2005 \\
\hline Hemalin & 20 & Kunitz & H. longicornis & Thrombin inhibitor & Liao et al., 2009 \\
\hline IxSc-1E1 & 45 & Serpin & I. scapularis & Thrombin inhibitor & Ibelli et al., 2014 \\
\hline Americanin & 12 & - & A. americanum & Thrombin inhibitor & Zhu et al., 1997 \\
\hline Amblin & 17.4 & Kunitz & A. hebraeum & Thrombin inhibitor & Lai et al., 2004 \\
\hline Variegin & 3.7 & - & A. variegatum & Thrombin inhibitor & Kazimírová et al., 2002 \\
\hline Hyalomin 1-4 & $8.4,8.5,8.2,7.4$ & - & H. marginatum rufipes & Thrombin inhibitor & $\begin{array}{l}\text { Francischetti et al., 2011; } \\
\text { Jablonka et al., } 2015\end{array}$ \\
\hline NTI 1 & 3.4 & - & H. dromaderii & Thrombin inhibitor & Ibrahim et al., 2001a \\
\hline NTI 2 & 14.9 & - & H. dromaderii & Thrombin inhibitor & Ibrahim et al., 2001a \\
\hline Rhipilin-1 & 18 & Kunitz & R. haemaphysaloides & Thrombin inhibitor & Gao et al., 2011 \\
\hline RHS-1 & 41.9 & Serpin & R. haemaphysaloides & Thrombin inhibitor & Yu et al., 2013 \\
\hline RHS-2 & 42.7 & Serpin & R. haemaphysaloides & Thrombin inhibitor & Yu et al., 2013 \\
\hline Calcaratin & 14.5 & - & R. B. calcaratus & Thrombin inhibitor & Motoyashiki et al., 2003 \\
\hline- & & - & I. holocyclus & Thrombin inhibitor & Anastopoulos et al., 1991 \\
\hline Ornithodorin & 12 & Kunitz & O. moubata & Thrombin inhibitor & van de Locht et al., 1996 \\
\hline Savignin & 12 & - & O. savignyi & Thrombin inhibitor & Mans et al., 2002 \\
\hline Monobin & 15 & Kunitz & A. monolakensis & Thrombin inhibitor & Mans et al., 2008 \\
\hline
\end{tabular}


TABLE 1 | Continued

\begin{tabular}{|c|c|c|c|c|c|}
\hline Inhibitor name & $\begin{array}{c}\text { Molecular } \\
\text { weight (kDa) }\end{array}$ & Inhibitor type & Tick species & Action & References \\
\hline \multicolumn{6}{|c|}{ HOST-IMMUNE SYSTEM MODULATION BY TICK FACTORS } \\
\hline BmSl-7 & 7.3 & - & R. (B.) microplus & Elastase inhibitor & Sasaki et al., 2008 \\
\hline Lopsins & $43-44$ & Serpin & A. americanum & Probable anti-inflammatory action & Mulenga et al., 2007 \\
\hline AamS6 & 42 & Serpin & A. americanum & $\begin{array}{l}\text { Inhibits elastase, plasmin, and } \\
\text { chymase }\end{array}$ & $\begin{array}{l}\text { Chalaire et al., 2011; } \\
\text { Syrovets et al., } 2012\end{array}$ \\
\hline AAS19 & 43 & Serpin & A. americanum & Inhibits plasmin & $\begin{array}{l}\text { Syrovets et al., 2012; Kim } \\
\text { et al., 2015, } 2016\end{array}$ \\
\hline Iris & 43 & Serpin & I. ricinus & $\begin{array}{l}\text { Inhibits elastase-like proteases and } \\
\text { suppresses pro-inflammatory } \\
\text { cytokine secretion }\end{array}$ & $\begin{array}{l}\text { Leboulle et al., } 2002 a ; \\
\text { Prevot et al., } 2009\end{array}$ \\
\hline Ipis-1 & 41.7 & Serpin & I. persulcatus & Modulates CD14+ cells activation & Toyomane et al., 2016 \\
\hline IRS-2 & 41.9 & Serpin & I. ricinus & $\begin{array}{l}\text { Modulates T cell differentiation, T17 } \\
\text { cell maturation and inhibits chymase } \\
\text { and cathepsin G }\end{array}$ & Chmelar et al., 2011 \\
\hline Tryptogalinin & 10.3 & Kunitz & I. scapularis & $\begin{array}{l}\text { Inhibits elastase, tryptase, plasmin, } \\
\text { matryptase }\end{array}$ & $\begin{array}{l}\text { Payne and Kam, 2004; Dai } \\
\text { et al., 2012; Valdés et al., } \\
2013\end{array}$ \\
\hline Tdpi & 11.1 & Kunitz & R. appendiculatus & Inhibits plasmin and tryptase & Paesen et al., 1999, 2007 \\
\hline RMS-3 & 40 & Serpin & R. (B.) microplus & $\begin{array}{l}\text { Probable interaction/modulation of B } \\
\text { cell action }\end{array}$ & Rodriguez-Valle et al., 2012 \\
\hline $\mathrm{BmTl} 2$-3 & $17,1,3.1$ & Kunitz & R. (B.) microplus & Inflammatory response modulation & Sasaki et al., 2004 \\
\hline \multicolumn{6}{|c|}{ HOST ANGIOGENESIS MODULATION AND APOPTOSE INDUCTION BY TICK FACTORS } \\
\hline $\mathrm{BmCl}$ & 6.5 & Kunitz & R. (B.) microplus & $\begin{array}{l}\text { Pro-apoptotic role and inhibits cell } \\
\text { proliferation }\end{array}$ & Lima et al., 2010 \\
\hline Haemangin & 14.1 & Kunitz & I. scapularis & $\begin{array}{l}\text { Abolishes angiogenesis and } \\
\text { neovascularization }\end{array}$ & Islam et al., 2009 \\
\hline BmTl-A & 13.5 & Kunitz & R. (B.) microplus & $\begin{array}{l}\text { Inhibits plasma kallikrein, plasmin, } \\
\text { and elastase, cell proliferation and } \\
\text { migration }\end{array}$ & Soares et al., 2012, 2016 \\
\hline Amblyomin-X & 13.5 & Kunitz & A. cajennense & $\begin{array}{l}\text { Tumor cell cycle alteration, } \\
\text { proteasome inhibitor, caspase } \\
\text { cascade activation, angiogenesis } \\
\text { repressor }\end{array}$ & $\begin{array}{l}\text { Chudzinski-Tavassi et al., } \\
\text { 2010; Morais et al., } 2016\end{array}$ \\
\hline \multicolumn{6}{|c|}{ ROLE IN TICK-BORNE PATHOGEN TRANSMISSION AND DEVELOPMENT } \\
\hline $\mathrm{BmTl}-\mathrm{A}$ & 13.5 & Kunitz & R. (B.) microplus & Limits $B$. bovis proliferation in ticks & Rachinsky et al., 2007 \\
\hline DvKPI & 62 & Kunitz & D. variabilis & Modulates Rickettsia development & Ceraul et al., 2008 \\
\hline |rSP| & 12 & Kunitz & I. ricinus & $\begin{array}{l}\text { Modulates Bartonella henselae } \\
\text { development }\end{array}$ & Liu et al., 2014 \\
\hline Ixophilin & 54.4 & Kunitz & 1. scapularis & $\begin{array}{l}\text { Probable role in B. burgdorferi } \\
\text { development }\end{array}$ & Narasimhan et al., 2013 \\
\hline \multicolumn{6}{|c|}{ TICK MOLECULES TESTED IN VACCINE PROJECTS } \\
\hline RAS-1 & 41.9 & Serpin & R. appendiculatus & $\begin{array}{l}\text { Impacts engorgement and tick } \\
\text { viability }\end{array}$ & Imamura et al., 2006 \\
\hline RAS-2 & 42.7 & Serpin & R. appendiculatus & $\begin{array}{l}\text { Impacts engorgement and tick } \\
\text { viability }\end{array}$ & Imamura et al., 2006 \\
\hline BmTls & $6.2-18.4$ & Kunitz & R. (B.) microplus & $\begin{array}{l}\text { Impacts tick viability and engorged } \\
\text { tick weight }\end{array}$ & Andreotti et al., 2002 \\
\hline HLS-1 & 41 & Serpin & H. longicornis & $\begin{array}{l}\text { Impacts tick viability and the } \\
\text { developmental cycle }\end{array}$ & Sugino et al., 2003 \\
\hline RmLTI & 46 & Kunitz & R. (B.) microplus & $\begin{array}{l}\text { Impacts egg eclosion, viability, and } \\
\text { larval hatchability }\end{array}$ & Andreotti et al., 2012 \\
\hline
\end{tabular}

categories: trapping inhibitors including the serpins and the $\alpha 2$ macroglobulines $(\alpha 2 \mathrm{M})$; and tight-binding inhibitors including the Kunitz or Kazal domain-containing proteins (Figure 1).
Trapping inhibition results in proteolytic cleavage, whereas proteases bound to tight-binding inhibitors can be released undamaged, while the inhibitors are liberated in either native 


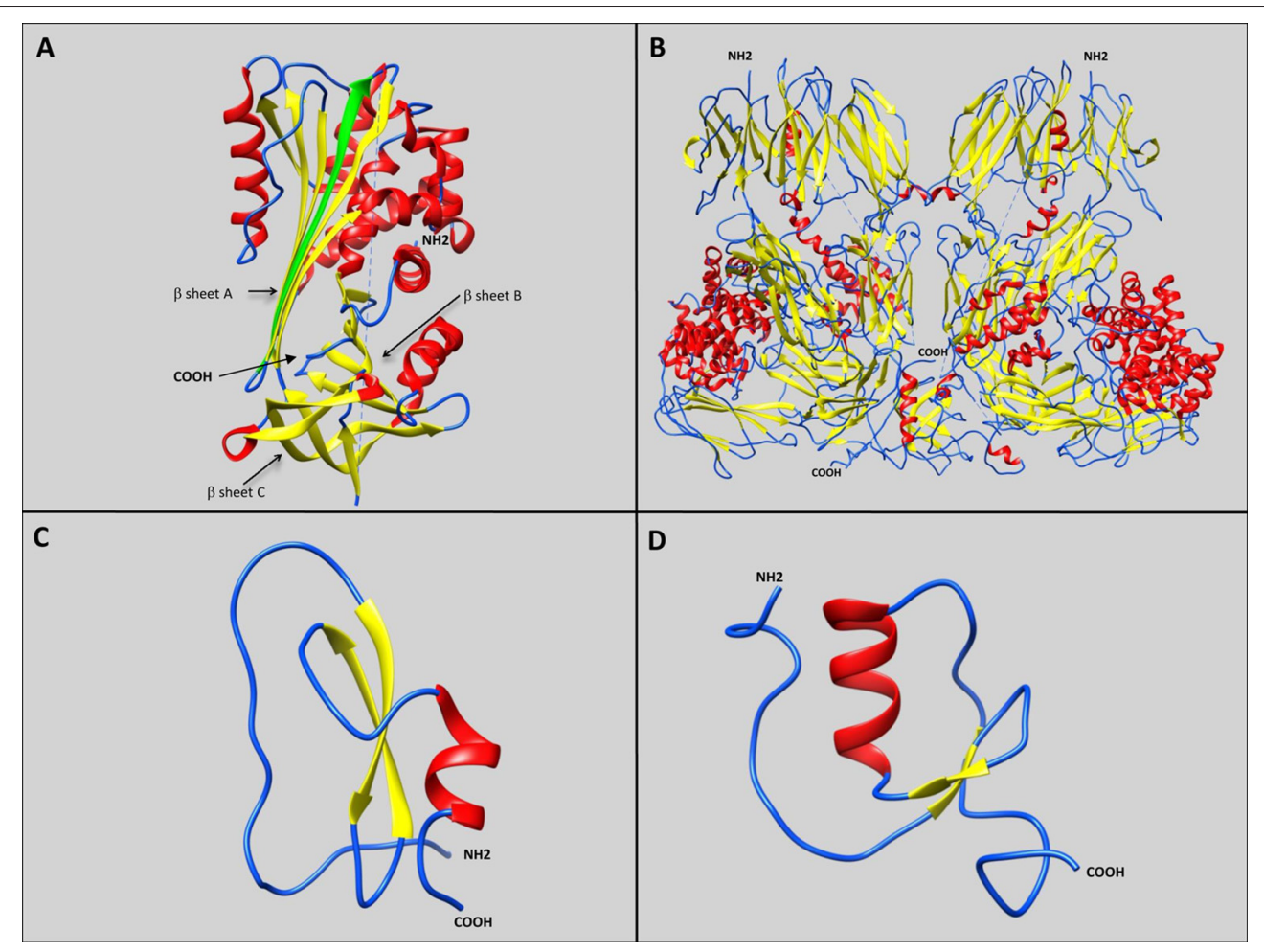

FIGURE 1 | Representative schematic diagrams of secondary structures of the four types of serine protease inhibitors: serpins, $\alpha 2$ macroglobulins, Kunitz-type inhibitors, and Kazal-type inhibitors. Loops, $\beta$-sheets, and $\alpha$-helices are labeled with blue, yellow, and red, respectively. (A) IRS 2 serpin from the I. ricinus tick showing the three $\beta$-sheets A, B, and C (Chmelar et al., 2011; PDB accession number: 3NDA). The green arrow represents the additional strand (s4A) formed after proteolysis, resulting in Reactive Center Loop cleavage, and insertion of the amino-terminal portion into the A $\beta$-sheet. (B) Human $\alpha 2$ macroglobulin complement component 5 in native homodimer conformation (Fredslund et al., 2008; PDB accession number: 3CU7). (C) Kunitz-type inhibitor Tick-Derived Protease Inhibitor (TDPI) from R. appendiculatus harboring one Kunitz domain composed of $\beta$-sheets and an $\alpha$-helix stabilized by three highly conserved disulphide bridges (Paesen et al., 2007; PDB accession number: 2UUX). (D) Kazal-type inhibitor Dipetalin from blood-sucking insect Dipetalogaster maximus. harboring one Kazal domain composed of one $\alpha$-helix with adjacent B-sheets and loop (Schlott et al., 2002; PDB accession number: 1KMA).

or cleaved forms. Target-protease interaction occurs via the reactive center loop (RCL), which demonstrates a range of different conformations and a high degree of conformational flexibility, with each inhibitor family displaying characteristic serine protease inhibitory mechanisms. Serine protease inhibitors can be classified into two functional groups based on their ability to inhibit either trypsin or chymotrypsin: inhibitors of trypsinlike proteases such as thrombin, or inhibitors of chymotrypsinlike proteases such as elastase.

\section{Trapping Inhibitors \\ Serpins}

Serpins form a large group of homologous proteins that appear to be ubiquitous in multicellular eukaryotes. They are composed of approximately 400 amino acids and are often glycosylated. Serpins fold into an $\mathrm{NH}_{2}$-terminal helical domain and a $\mathrm{COOH}$-terminal beta-sheet domain (Figure 1A). The serpin fold consisting of three beta-sheets (A-C) with eight or nine alphahelical linkers and an exposed $\sim 20$ residue RCL acts as bait for the protease target (Gubb et al., 2010). An unusual aspect of serpins is their native unstable fold, where the RCL is on top and the beta-sheet A is outward. Following proteolysis however, the RCL is cleaved, and the RCL amino-terminal portion inserts into the center of beta-sheet A to form an additional (fourth) strand (s4A), which effectively stabilizes the complex structure (Law et al., 2006). The protease is thus denatured and the serpin/protease complex is targeted for degradation (Huntington et al., 2000). This amino-terminal RCL insertion can either occur upon proteolytic cleavage, or spontaneously (Huntington, 2011). Hence serpins interact with their target via a "suicide-cleavage" mechanism, resulting in the formation of an inactive covalently linked serpin/protease complex. While the majority of serpins inhibit serine proteases, they can also bind to several others such as cysteine proteases, metalloproteases, caspases (Ray et al., 1992), papain-like cysteine proteases (Irving et al., 2002), as well as some non-protease ligands, such as collagen, DNA, or protein Z. Serpins have also been ascribed several additional roles, such as heparin or heparin sulfate co-factor (Khan et al., 2011), as well as rare non-inhibitory functions; as a hormone transporter (Pemberton et al., 1988), molecular chaperone (Nagata, 1996), or tumor suppressor (Zou et al., 1994).

\section{$\alpha 2-$ Macroglobulins}

Members of $\alpha 2$-macroglobulin ( $\alpha 2 \mathrm{M}$ ) group have been identified in a broad spectrum of vertebrate and invertebrate species and comprise the C3, C4, and C5 components of the vertebrate complement system (Sottrup-Jensen et al., 1985). $\alpha 2 \mathrm{Ms}$ are considered as early-acting innate immunity components, similar 
to opsonin, but their role in the proteolytic attack of invading pathogens remains hypothetical. Most $\alpha 2 \mathrm{Ms}$ are tetramers assembled from pairwise subunits with disulfide-bridges, but monomeric and dimeric forms also exist, the latter more common in invertebrates (Figure 1B) (Starkey and Barrett, 1982). Interaction with targeted proteases is initiated by proteolytic cleavage at a defined motif characterized by an exposed and highly flexible 30-40 amino acid residue region (Sottrup-Jensen, 1989). The inhibitory activity of $\alpha 2 \mathrm{Ms}$ is directly due to their thiol-ester bond, which can be abolished by small amines such as methylamine (Larsson and Bjork, 1984). This bait region with multiple cleavage sites inhibits a broad range of proteases including serine-, cysteine-, aspartic- and metalloproteases (Sottrup-Jensen, 1989). In addition, $\alpha 2 \mathrm{Ms}$ could play a role as hormone transporters (Peslova et al., 2009), and can counteract inhibition from other high molecular weight inhibitors by protecting protease active sites (Armstrong et al., 1985).

\section{Tight-Binding Inhibitors Kunitz/BPTI Inhibitors}

Initially discovered at high concentrations in beans, Kunitz proteins are typically small proteins with a molecular weight close to or less than $20 \mathrm{kDa}$ (Kunitz, 1945). The most wellstudied inhibitor from this family is the bovine pancreatic trypsin inhibitor (BPTI) that gives the family its name (Creighton, 1975). Generally they contain between one to twelve Kunitz domains (Laskowski and Kato, 1980), and each domain encloses disulphide-rich $\alpha$ helices and $B$-folds stabilized by three highlyconserved disulphide bridges, leading to a compact and stable molecule (Ranasinghe and McManus, 2013) (Figure 1C). Inhibitors of this kind possess a bait region inhibiting targeted proteases that precisely matches the enzyme's catalytic site, thus generating a particularly stable substrate/inhibitor complex (Ram et al., 1954). Through the RCL region, inhibitors block the serine protease active site with a tight non-covalent interaction without any conformational changes -similarly to enzymesubstrate Michaelis complex- forming a B-sheet between the enzyme and its inhibitor (Ascenzi et al., 2003; Krowarsch et al., 2003; Chand et al., 2004). Despite opening of the bait ring region following proteolysis, the free cut ends tend to maintain the initial fold, so the hydrolysis reaction is likely to be reversible with an equilibrium between cleaved and uncleaved [inhibitor/protease] complexes (Laskowski and Qasim, 2000). The tight-binding exposed RCL loop of Kunitz/BPTI inhibitors is suited to a wide variety of protein folds suggesting a large range of possible protease targets. However, some Kunitz domaincontaining proteins with RCL region substitutions have other functions such as ion channel blockers or snake toxins (Grzesiak et al., 2000).

\section{Kazal Inhibitors}

Initially identified in vertebrates, Kazal inhibitors have also been identified in several invertebrates (Rimphanitchayakit and Tassanakajon, 2010). They can carry from two to fifteen Kazal domains (Rawlings et al., 2004), which have between 40 and
60 amino acids of variable sequence, except for six wellconserved cysteine residues able to form three disulfide-linked sub-domains (Cerenius et al., 2010; Rimphanitchayakit and Tassanakajon, 2010). These domains comprise one $\alpha$ helix with three adjacent $\beta$ sheets and loops, that precisely fit the active sites of targeted proteases and block them stoichiometrically, resulting in a relatively stable protease/inhibitor complex (Figure 1D) (Laskowski and Kato, 1980). Although non-covalent binding occurs, Kazal inhibitor and protease association is tight, resulting in strong inhibition (Somprasong et al., 2006; Wang et al., 2009). Interactions between Kazal domains and proteases can occur via multiple different amino acids, thus influencing binding intensity and specificity. This enables the inhibition of several targets including trypsin, plasmin, porcine pancreatic elastase (PPE), human neutrophil elastase (hNE), chymotrypsin, proteinase $\mathrm{K}$, or thrombin (Rimphanitchayakit and Tassanakajon, 2010).

\section{ROLE OF SERINE PROTEASE INHIBITORS IN TICK BIOLOGY}

\section{Tick Immune System}

It is well known that ticks possess innate immunity that also affects their vector competence (Hajdusek et al., 2013). Although all of the involved mechanisms have not yet been fully clarified, microbe phagocytosis by tick hemocytes seems to be coupled to a primitive complement-like system, a variety of antimicrobial peptides and possibly reactive oxygen species (Kopacek et al., 2010). Studies in both hard and soft ticks have implicated several tSPIs in immune responses against different microbes, mostly identified in hemolymph (Figure 2, Table 2).

The most studied tick species in this context is $R$. (B.) microplus. Firstly, Ixodidin, a tSPI discovered in hemocytes, was reported to have strong inhibitory activity against Micrococcus luteus and, to a lesser extent against Escherichia coli (Fogaça et al., 2006). In addition to this bacterial clearance role, Ixodidin also possesses inhibitory activity against chymotrypsin and elastase serine proteases (Fogaça et al., 2006). However, it remains unclear whether the antimicrobial activity is due to protease inhibition or directly through peptide effects on bacterial membranes. Two additional inhibitors have been identified from R. (B.) microplus eggs: BmSI 6 and BmSI 7 (Boophilus microplus subtilisin inhibitors), that target Pr1 proteases from Metarhizium anisopliae, a fungus used as a biological insecticide (Sasaki et al., 2008). These Pr1 proteases induce host cuticle degradation, enabling hyphae penetration to obtain nutrition (Leger et al., 1987). Only BmSI 7-which shares several similarities with Ixodidin-has been well characterized. It harbors disulphide bonds and a trypsin inhibitor-like cysteinerich domain (TIL), and as it is expressed in adult ovaries, midgut, SGs, hemocytes, body fat, and larvae, it could be involved in tick defense mechanisms, and/or in avoiding tick tissue degradation (Sasaki et al., 2008). Random sequencing of a tick body fat cDNA library enabled the discovery of, BmCI (Boophilus microplus chymotrypsin inhibitor), a chymotrypsin inhibitor that belongs to the Kunitz/BPTI inhibitor family (Lima et al., 2010). 


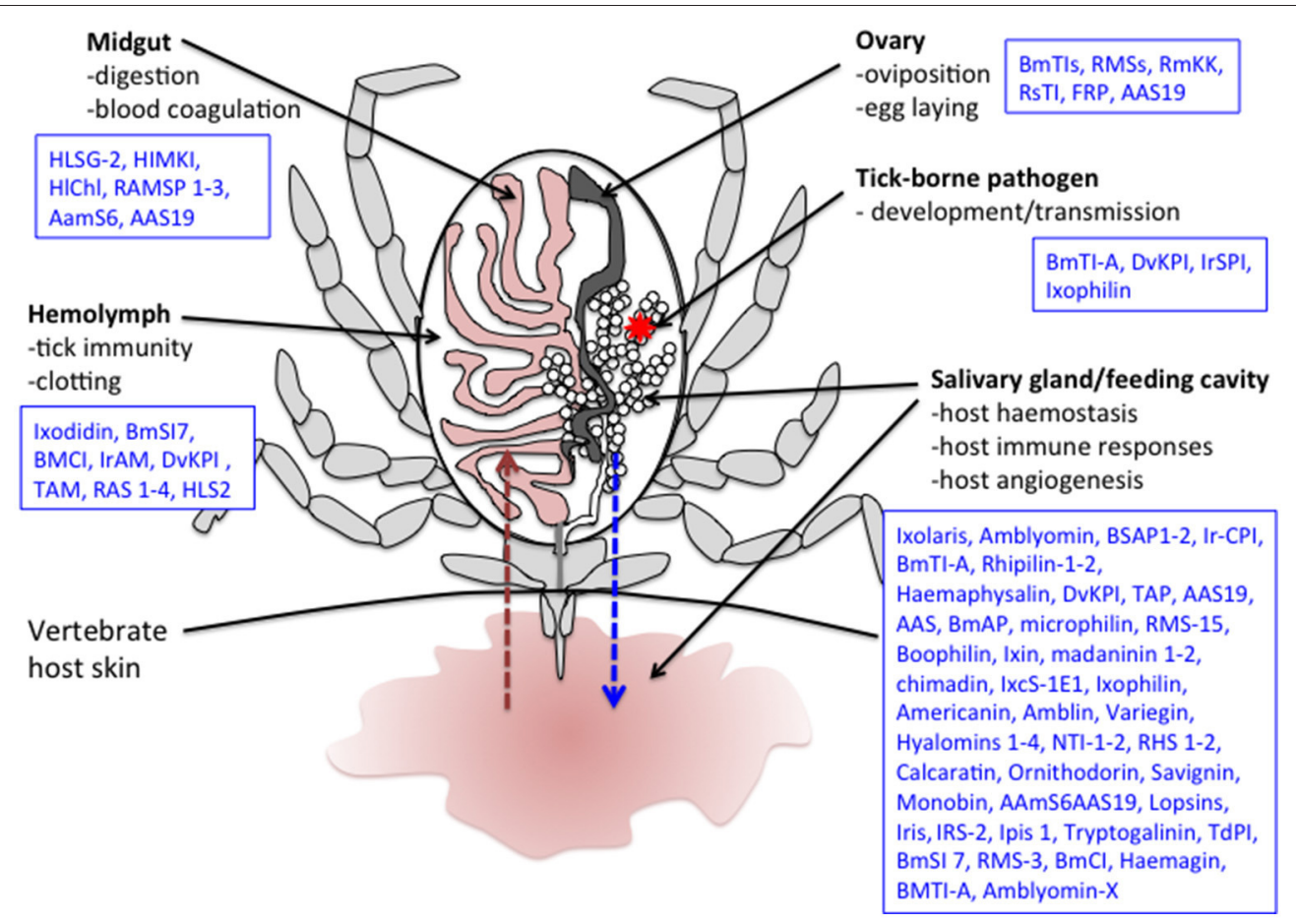

FIGURE 2 | Schematic representation of a tick during feeding. Several tick serine protease inhibitors identified in different tick species and implicated in both tick biology/physiology and modulation of the vertebrate host responses to tick bite are also indicated. The red arrow represents blood absorption. The blue arrow represents saliva injection. The red star corresponds to a tick-borne pathogen. Note that only half of the digestive tract and a single salivary gland and ovary are represented here. Boophilus microplus subtilisin inhibitors (BmSI); Boophilus microplus Chymotrypsin inhibitor (BmCl); Ixodes ricinus alpha macroglobuline (IrAM); Dermacentor variabilis Kunitz protease inhibitor (DvKPI); Tick $\alpha$-Macroglobulin (TAM); Boophilus microplus trypsin inhibitor (BmTIs); R. appendiculatus Serpins (RAS); H. longicornis serine proteinase genes (HLSG); Haemaphysalis longicornis midgut Kunitz-type inhibitor (HIMKI); Haemaphysalis longicornis serpin (HLS); Haemaphysalis longicornis chymotrypsin inhibition (HIChl); R. appendiculatus Midgut Serine proteinases (RAMSP); R.B. microplus Serpin (RMS); Amblyomma americanum serpin 6 (AamS6); Amblyomma americanum serpin 19 (AAS19); R.B. microplus Kunitz kallikrein inhibitor (RmKK); I. ricinus contact phase inhibitor (IrCPI); Tick Anticoagulant Protein (TAP); Boophilus microplus Anticoagulant Protein (BmAP); B. microplus gut thrombin inhibitor (BmGT); Nymph thrombin inhibitor (NTI); Rhipicephalus haemaphysaloides serpin (RHS); I. ricinus immunosuppressive (Iris); I. ricinus serpin (IRS); Ixodes persulcatus immunosuppressive (Ipis); I. ricinus serine protease inhibitor (IrSPI); R. microplus Larval Trypsin Inhibitor (RmLTI).

BmCI strongly and specifically inhibits chymotrypsin, and also hNE with reduced specificity. BmCI gene expression analysis demonstrated higher expression in hemocytes and ovaries than in SGs and body fat. Following infection with M. anisopliae, increased BmCI expression was only observed in tick hemocytes clearly suggesting a role in the tick defense system (Lima et al., 2010). Finally, among BmTIs (Boophilus microplus trypsin inhibitors) identified in both larvae and eggs (Tanaka et al., 1999), a double Kunitz-containing inhibitor, BmTI-A, had increased transcript levels in ovaries following Babesia bovis infection (normally transmitted transovarially in ticks), also suggesting a probable role in the tick immune system (Rachinsky et al., 2007).

IrAM ( $I$. ricinus alpha macroglobuline), was identified in the hemolymph of $I$. ricinus as a $\alpha 2 \mathrm{M}$ composed of two noncovalently linked subunits (Buresova et al., 2009). Alternative splicing occurring during IrAM synthesis generates seven bait variants, increasing the spectrum of targeted proteases. IrAM transcripts are detected throughout all tick developmental stages. Gene expression was higher in SGs from partially engorged females than in hemocytes or ovaries, even though IrAM protein is only detected in tick hemocytes. RNAi experiments revealed that IrAM is not involved in tick fitness, mortality, or fecundity (Buresova et al., 2009). However, IrAM enhanced phagocytosis and elimination of the bacteria Chryseobacterium indologenes due to its active thioester bonds, which was not observed with other bacteria such as $B$. burgdorferi (Buresová et al., 2006; Buresova et al., 2009). IrAM likely interacts with the major $C$. indologenes virulence factor, a metalloprotease, suggesting a role in the tick immune system during phagocytosis of metalloprotease-producing bacteria (Buresova et al., 2009).

Following the discovery of over-expressed genes in Dermacentor variabilis tick body fat and midgut in response to Rickettsia montanensis infection (Ceraul et al., 2007), several Kunitz/BPTI inhibitors were identified including DvKPI (Dermacentor variabilis Kunitz protease inhibitor with five Kunitz domains) (Ceraul et al., 2008). DvKPI was up-regulated six-fold in infected ticks that had fed for three days. These results suggested that DvKPI is involved in tick responses to Rickettsia, avoiding massive colonization which would be detrimental to ticks. 
TABLE 2 | Antimicrobial activities of serine protease inhibitors of ticks (tSPI).

\begin{tabular}{|c|c|c|c|}
\hline $\begin{array}{l}\text { Targeted } \\
\text { microbe }\end{array}$ & tSPI & Tick species & References \\
\hline $\begin{array}{l}\text { Micrococcus } \\
\text { luteus }\end{array}$ & Ixodidin & R. (B.) microplus & Fogaça et al., 2006 \\
\hline Escherichia coli & Ixodidin & R. (B.) microplus & Fogaça et al., 2006 \\
\hline \multirow{2}{*}{$\begin{array}{l}\text { Metarhizium } \\
\text { anisopliae }\end{array}$} & $\mathrm{BmSI} 6, \mathrm{BmSI} 7$ & R. (B.) microplus & Sasaki et al., 2008 \\
\hline & $\mathrm{BmCl}$ & & Lima et al., 2010 \\
\hline Babesia bovis & BmTl-A & R. (B.) microplus & Rachinsky et al., 2007 \\
\hline $\begin{array}{l}\text { Chryseobacterium } \\
\text { indologenes }\end{array}$ & IrAM & 1. ricinus & Buresova et al., 2009 \\
\hline $\begin{array}{l}\text { Rickettsia } \\
\text { montanensis }\end{array}$ & DvKPI & D. variabilis & Ceraul et al., 2007 \\
\hline $\begin{array}{l}\text { Bartonella } \\
\text { henselae }\end{array}$ & IrSPI & I. ricinus & Liu et al., 2014 \\
\hline $\begin{array}{l}\text { Borrelia } \\
\text { burgdorferi }\end{array}$ & Ixophilin & I. scapularis & $\begin{array}{l}\text { Narasimhan et al., } \\
2013\end{array}$ \\
\hline
\end{tabular}

Several tSPIs have also been identified in Ornithodoros moubata soft tick hemolymph, including TAM, (tick $\alpha$ macroglobulin), the second most abundant protein after vitellogenin (Kopacek et al., 2000). TAM is a tetrameric glycosylated protein that displays similar structural features present on IrAM, and exerts inhibitory activity against both trypsin and thermolysin (Kopacek et al., 2000). Comparing the conserved cysteine motifs between human and limulus $\alpha 2 \mathrm{Ms}$ enables the prediction of disulfide bridge patterns which explain the atypical molecular arrangement of the four TAM bait region variants, likely arising from alternate splicing (Saravanan et al., 2003). While TAM was initially detected in tick hemocytes, significant up-regulation has also been reported in SGs and gut after 1 day of feeding (Saravanan et al., 2003). TAM is believed to be involved in tick defense systems, but an additional role as an anti-coagulant has also been postulated (Keller et al., 1993; van de Locht et al., 1996).

\section{Hemolymph Clotting Formation}

As for vertebrates, effective clotting is critical in ticks to limit hemolymph loss and to inhibit pathogens from entering into the tick through the wound. Little is known about the proteins involved in tick hemolymph clotting but several tSPIs have been implicated in this defense system due to homology with known proteins (Figure 2).

Four Rhipicephalus appendiculatus tick serpins have been identified as potential clotting enzymes involved in the hemolymph coagulation cascade: $R$. appendiculatus serpin-1, 2, -3, and -4 (RAS-1, -2, -3, and -4) (Mulenga et al., 2003b). All exhibit similarities ranging from 25 to $30 \%$ with limulus intracellular coagulation inhibitor type 1 (LICI-1) from the Japanese horseshoe crab Tachypleus tridendatus. RAS-3 harbors also amino acids similarities with LICI-2 and is comparably expressed in all tick organs, while RAS-1, -2 and -4 expression was stronger in SGs than in other tick organs (Mulenga et al., 2003b).
HLS2, a serpin from Haemaphysalis longicornis, contains an RCL with high sequence similarities to both vertebrate and invertebrate serpins, and may interact with both chymotrypsin and thrombin (Imamura et al., 2005). HLS2 also demonstrates similar molecular features to RAS-3 and LICI, and its mRNA has only been detected in the hemolymph of partially or fully engorged nymphs and females, suggesting a possible role in endogenous hemolymph circulation. In the same tick species, the serpin HLSG-1 harbors high similarity (32-44\%) to Japanese and mangrove horseshoe crab clotting factor $\mathrm{C}$ precursors, mouse manan-binding lectin serine protease 1 , and rat/mouse hepsin proteins (Mulenga et al., 2001). In partially fed ticks HLSG-1 transcripts were weakly expressed in the midgut and strongly detected in the SGs.

\section{Blood Uptake and Digestion Modulation}

As strict haematophagous acari, ticks require blood meals to complete their development and reproduction. These arthropods are pool-feeders and create haemorrhagic pools from which they collect nutritive fluids while biting, and interestingly, some female hard ticks can imbibe enough blood to increase in size by as much as 100 times (Sonenshine and Anderson, 2014). This unique feeding method implies the existence of very effective blood uptake and digestion mechanisms, in which several tSPIs have now been implicated (Figure 2).

In 2001, Mulenga et al. identified HLSG-2 in H. longicornis ticks, a serpin with chymotrypsin-like protease selectivity (Mulenga et al., 2001). HLSG-2 transcripts were only detected in partially fed ticks and expression increased in parallel with feeding duration. HLSG-2 expression was strong in midgut and weak in salivary glands, suggesting probable links with blood uptake and digestion processes (Mulenga et al., 2001). In the same tick species, another serpin-1 (HLS-1) harboring similarities to the $I$. ricinus SG serpins RAS-2 and RAS1 (Sugino et al., 2003) was identified. Taking into account additional sequence homologies with other anticoagulation factors, its specific expression in midgut of partially fed ticks, as well as the fact that clotting time can be delayed by HLS-1 in a dose-dependent manner, all indicate that HLS1 has a probable role in tick blood meal uptake as well as maintaining blood fluidity in the midgut (Sugino et al., 2003). Then in 2010, Miyoshi et al. identified a Kunitztype tSPI exclusively expressed in the midgut of adult ticks named HIMKI (Haemaphysalis longicornis midgut Kunitz-type inhibitor) (Miyoshi et al., 2010). Immunofluorescent analysis demonstrated that HlMKI likely interacts with HISP, a hemolytic serine protease expressed in the tick midgut, and that both proteins harbored similar expression patterns with a $72 \mathrm{~h}$ peak during feeding (Miyoshi et al., 2007). HlMKI displayed inhibitory activity against the HISP protein, and against chymotrypsin and elastase to a lesser extent. Altogether these results suggested that HIMKI can regulate blood digestion in tick midgut via HlSP modulation (Miyoshi et al., 2010). Lastly, another Kunitztype tSPI was identified in $H$. longicornis hemocytes, and was named HlChI because of its chymotrypsin inhibitory profile (Alim et al., 2012). HlChI has strong chymotrypsin inhibitory activity but low trypsin inhibitory activity. The HlChI 
gene is expressed in larvae, nymphs, and adults during all feeding phases, and transient up-regulation has been clearly detected from feeding initiation to repletion. During feeding, $\mathrm{HlChI}$ is mainly localized in hemocytes, though low expression levels were also detected in midgut, salivary glands, ovaries, and the epidermis (Alim et al., 2012). Several HlChI-RNAiinjected ticks died $48 \mathrm{~h}$ after feeding, while others ingested significantly smaller and slower blood meals, laid fewer eggs, and demonstrated lower larvae conversion (Alim et al., 2012). During feeding, HlChI expression in hemocytes peaks at $96 \mathrm{~h}$, coinciding with low proteolytic activity and a low homeostasis level maintained by a few principal inhibitors (Franta et al., 2010; Alim et al., 2012). Thus HlChI is likely an indirect but essential actor in both vital blood feeding and tick reproduction processes.

In $R$. appendiculatus ticks, three serine protease inhibitors of chymotrypsin or trypsin and named RAMSP 1-3 $(R$. appendiculatus midgut serine proteinases 1-3) were identified, and are likely involved in feeding processes or blood digestion (Mulenga et al., 2003a). RAMSP-1 and -2 transcripts have only been detected in partially fed ticks, while RAMSP-3 mRNA was detected in both unfed and partially fed ticks, with stronger signals in the latter. RAMSPs expression is not restricted to the midgut because RAMSP-1 is equivalently expressed in all tick organs, while RAMSP-2 is weakly expressed in both SGs and midgut, and RAMSP-3 is more weakly expressed in SGs than midgut (Mulenga et al., 2003a). Additionally, all three RAMSPs are expressed in tick carcasses (whole tick without SGs and midgut), suggesting widespread distribution of these inhibitors in other tick tissues (Mulenga et al., 2003a). In terms of RAS serpins, RAS- 1 and RAS- 2 mRNAs can be detected at all life stages, as well as in both sexes, with positive detection in 4-day partially fed and fully engorged ticks (Mulenga et al., 2003b). This suggests gene expression both during and after feeding, although they were not expressed in saliva, likely because they do not contain signal peptide sequences (Mulenga et al., 2003b). Indeed, RAS-1 and RAS-2 might be associated with feeding in both SGs and the midgut by modulating blood uptake and digestion. Confirmation occurred when significantly fewer fully engorged nymphs were counted when ticks were fed on vaccinated compared to non-vaccinated cattle (Imamura et al., 2006).

Then in 2014, NGS technologies enabled the identification of 22 RMS serpins (RMS-1 to RMS-22) from $R$. (B.) microplus (Tirloni et al., 2014a,b), among which 18 full-length coding sequences were identified (Rodriguez-Valle et al., 2015). While serpin consensus patterns were conserved, these 18 members of the RMS family showed high amino acid sequence variability suggesting a broad spectrum of targeted serine proteases. Transcription levels of RMS-13, -15, -16 in SGs, or RMS-6, $7,-9,-17$ in both SGs and the midgut, suggested that they play a role in the blood meal process, either in uptake or during digestion (Rodriguez-Valle et al., 2015). Functionally, RMS-3 strongly inhibits chymotrypsin and elastase, but only weakly trypsin and thrombin. RMS-15 is a strong thrombin inhibitor and RMS- 6 a chymotrypsin inhibitor. Finally while RMS- 21 and -22 are not secreted, they were detected in the midgut and SGs suggesting a probable role in proteolysis activity during blood digestion (Rodriguez-Valle et al., 2015). Among the previously mentioned R. (B.) microplus BMTIs, the Kunitz inhibitors BmTi $\mathbf{A}$ and BmTI D were also believed to play an important role in feeding by inhibiting human prekallikrein (HuPK) implicated in the coagulation cascade (Sasaki et al., 2004), thus facilitating blood fluid uptake.

The serpin AamS6 was identified in the Amblyomma americanum tick (Mulenga et al., 2013). Both AamS6 mRNA and protein are strongly expressed in the SGs and midgut in unfed ticks, as well as during the first $72 \mathrm{~h}$ of feeding, before fading at $96 \mathrm{~h}$, suggesting injection into the bite site and a role in tick anchorage to the host (Chalaire et al., 2011). As expected according to its serpin-like sequences, AamS6 interacted clearly and selectively with trypsin, chymotrypsin, elastase, and chymase, but also surprisingly with papain-like cysteine proteases, indicating that it is a cross-class protease inhibitor (Mulenga et al., 2013). In addition, AamS6 seems to transiently interact with fibrin-lysing plasmin. Despite only in vitro data providing the proof for plasmin-AamS6 interaction, it was hypothesized that this inhibitor could sustain blood flow to the tick feeding site and prevent clot formation (Mulenga et al., 2013). In this series of experiments, AamS6 only delayed recalcification time (RCT, the time to plasma clotting once calcium ions and blood-clotting co-factor(s) are reintroduced to citrate plasma), and did not inhibit any of the three coagulation pathways (extrinsic, intrinsic, and common, Figure 3). Platelet aggregation inhibition was also reported, that, when combined with previous results, bears out AamS6's involvement in inhibiting blood coagulation both in the midgut and via saliva secretion (Mulenga et al., 2013). Later, an $A$. americanum transcriptomic study identified a novel serpin, AAS19, which has the most fully conserved RCL among the ixodid ticks (Kim et al., 2015; Porter et al., 2015). The presence of the tripeptide Arg-Gly-Asp which constitutes a "RGD” motif, in the AAS19 sequence suggests a potential relationship between integrin GPIIb-IIIa and AAS19 during platelet aggregation (Nurden, 2014). Additionally, as AAS19 is abundantly and mostly expressed in the midgut at $96 \mathrm{~h}$ during feeding, it likely ensures that host blood doesn't clot during feeding (Porter et al., 2015). AAS19 demonstrates inhibitory activity against plasmin, FXa, and FXIa, and at a lower efficacy rate against FXIIa, FIIa (activated thrombin), FIXa, and tryptase, demonstrating its broad activity spectrum. In addition, the three coagulation pathways have delayed clotting in the presence of AAS19, likely due to weak thrombin inhibition. Altogether these results support AAS19 involvement in blood digestion (Kim et al., 2015).

Finally, Ixophilin was identified as a Kunitz thrombin inhibitor secreted in the midgut of I. scapularis and which shares homology with Hemalin and Boophilin (see below) (Narasimhan et al., 2013). Ixophilin was preferentially expressed in adult and nymphal midgut and was induced upon feeding, consistent with a potential role in preventing blood clotting in the midgut. In addition, Ixophilin mice immunization experiments demonstrated that ixophilin was necessary for efficient engorgement (Narasimhan et al., 2013). 


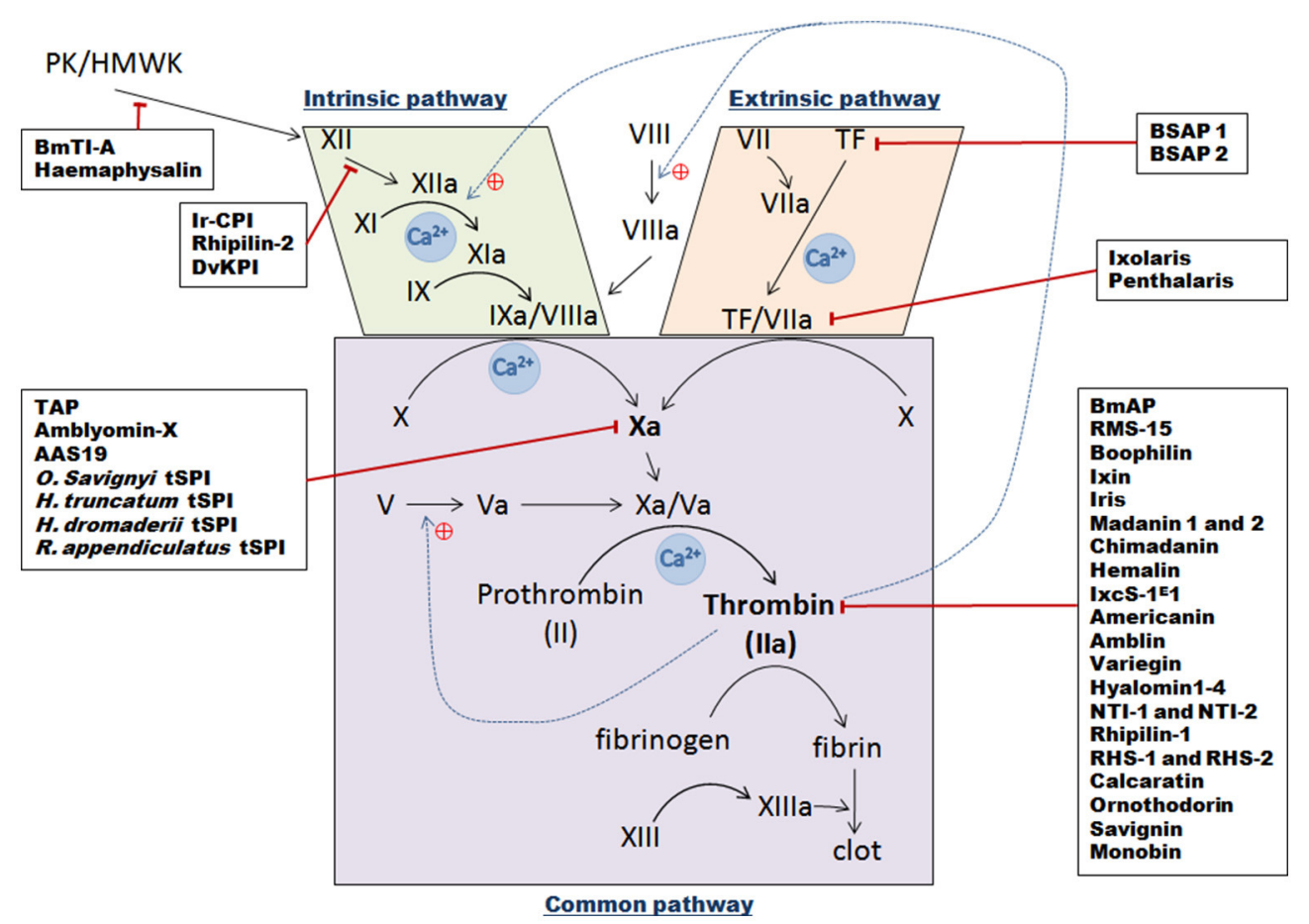

FIGURE 3 | Schematic overview of the three vertebrate blood coagulation cascade pathways, with indicated tick serine protease inhibitors and their targets. The intrinsic pathway is activated following a trauma and when blood comes into contact with subepithelial cells [contact phase with XII, Prekallikrein (PK), and High Molecular Weight Kininogen molecules (HMWK)], which then results in successive activation of factors XII, XI, and IX. The IXa/VIIla complex then activates transformation of factor $\mathrm{X}$ into factor $\mathrm{Xa}$. The extrinsic pathway is initiated following contact between Tissue Factor (TF) from vessels and circulating factor VII. After injury, they form a complex and catalyze the activation of factor X into factor Xa. Once activated by either pathway, factor Xa complexes with its cofactor Va to form the pro-thrombinase complex, which can then convert prothrombin into thrombin. Thrombin then transforms fibrinogen into fibrin to create a plug. Black arrows represent direct activation, dotted blue lines show positive thrombin feedback, red lines correspond to tSPI inhibition targets.

\section{Tick Development, Oviposition, Egg Laying}

Tick oviposition and egg laying are essential aspects of the tick life cycle determining tick population expansion. These processes are regulated by many proteins, including tSPIs (Figure 2). Inhibitors may be endogenous to certain organs and, for ovaries, it appears that some proteins-including tSPIs-can be captured from the midgut by receptor-mediated endocytosis followed by incorporation into the eggs (Tufail and Takeda, 2009).

Several tSPIs named BmTIs, with a similar target spectrum (trypsin, plasmin, and $\mathrm{HuPK}$ ), have been discovered in the eggs and larvae of R. (B.) microplus (Tanaka et al., 1999). However, differing concentrations and inhibitor specificity changes have been reported between egg and larval stages (Andreotti et al., 2001; Sasaki et al., 2004). Andreotti et al. showed a 69.7 and $71.3 \%$ reduction in both engorged tick number and egg weight respectively when female ticks were fed on BmTIs-immunized cattle, confirming a crucial role for BmTIs in egg production and development (Andreotti et al., 2002). BmTI-6, a Kunitz tSPI identified in ovaries, was also expressed in tick body fat and demonstrated specific inhibitory activity against trypsin and trypsin-like proteases, such as plasmin (Sasaki and Tanaka, 2008). As for other BmTIs, BmTI-6 is suspected to play a role in controlling endogenous proteases in the egg and larval stages (Andreotti et al., 2001; Sasaki et al., 2004).
The RMS-3 serpin is expressed in the SGs of semi-engorged females, but lower expression levels were also observed in the midgut and ovaries of $R$. (B.) microplus (Rodriguez-Valle et al., 2012). In vitro feeding assays showed that both egg weight and larval transformation rates were reduced in female ticks prefed on anti-RMS-3 sheep serum, thus implicating RMS-3 in reproduction and egg development (Rodriguez-Valle et al., 2012). An additional Kunitz serine protease inhibitor with trypsin and kallikrein inhibitory activities named RmKK was recently discovered in R. (B.) microplus eggs (Abreu et al., 2014). Although the native protein was obtained from eggs, the RmKK transcript was only detected in the midgut, suggesting possible midgut expression and subsequent transport to the ovaries and egg incorporation. Interestingly, kallikrein inhibitors were thought to protect against undesired egg proteolysis (Willadsen and Riding, 1980). Lastly, four other serpins were also recently implicated in tick embryogenesis regulation or vitellogenesis: RMS-19 and RMS-20, which are expressed in all tissues and at all stages, RMS$\mathbf{6}$ which is only detected in ovaries, and RMS-21 and -22 which are only detected in eggs (Rodriguez-Valle et al., 2015).

Studies on the dog tick Rhipicephalus sanguineus identified a group of proteins belonging to the Kunitz/BPTI tSPI family, called RsTIs in larval stages (Sant'Anna Azzolini et al., 2003). Three of which-RsTIQ2, RsTIQ7 and RsTIS5-inhibit trypsin, 
neutrophil elastase, and human plasmin. RsTIQ2, and to a lesser extent RsTIQ7, also inhibit HuPK (Sant'Anna Azzolini et al., 2003). Because RsTIs are similar in structure and inhibitory activity to previously described tSPIs from $R$. (B.) microplus, a similar role in egg production has been hypothesized.

A human follistatin-related-protein (FRP) homolog was also identified in H. longicornis ticks, and is implicated in tick oviposition (Zhou et al., 2006). This protein harbors three distinct domains, a follistatin-like domain, a Kazal domain and two EFh calcium-binding motifs. Polyclonal antibodies revealed FRP presence in tick salivary glands, midgut, body fat, hemocytes, and a strong expression in ovaries (Zhou et al., 2006). RNAi experiments silencing FRP in adult rabbit-fed ticks as well as the use of anti-FRP antibodies showed significant negative effects on tick oviposition while no differences were observed in feeding duration, engorgement weight, and survival (Zhou et al., 2006).

Finally, when the aforementioned A. americanum AAS19 gene was RNAi silenced, ticks imbibed much less blood and presented curious body deformities compared to controls, likely due to deficiencies in hemostasis regulation (Kim et al., 2016). In addition, ticks that fed on rAAS19-immunized rabbits took smaller blood meals and detached prematurely. Following a second round of infestation on these rabbits, ticks also failed to lay eggs, suggesting an important role for AAS19 in both tick homeostasis and reproduction (Kim et al., 2016).

\section{ROLES OF SERINE PROTEASE INHIBITORS IN MODULATING VERTEBRATE HOST RESPONSES}

The long feeding period of ticks necessitates extended control over the vertebrate host's haemostasis and immunity. During this feeding process, ticks alternatively inject saliva into and then absorb fluids from the bite wound. To enable the feeding process and avoid tick rejection, several salivary components are thought to control host responses, including several tSPIs (Figure 2).

\section{Anti-Hemostatic Effects of Tick Serine Protease Inhibitors}

Hemostasis in vertebrates is a tightly regulated process to avoid blood leakage following injury (Aird, 2003). Many biochemical mechanisms are involved in blood clot formation with a central enzymatic cascade that can be activated by three different pathways (Figure 3). When the vessel epithelium is damaged, tissue factors (TF) expressed by epithelium cells initiate clot cascades, leading to activation of extrinsic blood coagulation pathways. Displaying TF triggers factor VII activation thus forming TF/VIIa complexes which then activate central factor X. The second intrinsic pathway is activated by contact factorsXII, prekallikrein (PK) and high molecular weight kininogen (HMWK) - that cause successive activation of intermediate factors (factors XI, IX), and IXa/VIIIa complex formation, which also activates factor $\mathrm{X}$. Thus intrinsic and extrinsic coagulation pathways merge in order to activate Factor $\mathrm{X}$ to Xa. Then in the "common pathway," activated factor Xa interacts with its cofactor Va and forms the pro-thrombinase complex. This complex then processes pro-thrombin (factor II) into thrombin (factor IIa) that converts fibrinogen into fibrin which then polymerizes to constitute a clot. Ticks prevent clot formation in the host, in the micro hematoma at the bite site, but also, in tick mouthparts and midgut. They inject numerous proteins via their saliva into the blood bowl, mostly tSPIs that affect serine proteases or their zymogens (Factors II, VII, IX, X, XI, XII, and prekallikrein) implicated in clot formation (Tatchell, 1969; Ribeiro et al., 1985). As anticoagulant factors, these inhibitors are essential in allowing ticks to take their blood meal, and concomitantly ingest and transmit pathogens. In addition, during the long feeding period, the blood in the tick midgut is maintained in a fluid state until repletion. To retain blood fluidity, anticoagulants are secreted from the tick midgut epithelium to the midgut lumen. Coagulation inhibitors secreted into the midgut mostly inhibit thrombin whereas anticoagulants secreted from SGs mainly inhibit FXa.

\section{Extrinsic Pathway Tick Inhibitors}

I. scapularis was intensively studied in order to understand tick saliva anticoagulant properties, leading to the discovery of multiple anticoagulant molecules, the first being Ixolaris from the SGs (Francischetti et al., 2002). This inhibitor, similar to human hTFPI (tissue factor pathway inhibitor), contains two Kunitz domains. Ixolaris, like hTFPI, either blocks FVIIa/TF complex activity through direct interaction with the active site, or sterically via the formation of a tight complex [FVIIa/TF/Ixolaris/FX(a)], resulting in effective extrinsic pathway inhibition (Francischetti et al., 2002). Ixolaris, reaching high concentrations only in the feeding cavity in vivo, behaves as a fast ligand of the FX and FXa heparin binding exosite (HBE) - a site distinct from the FXa reactive sitepresumably via its second atypical Kunitz domain (Monteiro et al., 2005). The prothrombinase complex could be resistant to physiological concentrations of Ixolaris due to competition with its prothrombin substrate, as reported for hTFPI (Mast and Broze, 1996). Ixolaris' mechanism of action was then proposed to be competitive and concentration dependent (Monteiro et al., 2005). Further analyses of an SG cDNA library enabled the discovery of another Kunitz domain protein implicated in coagulation inhibition, Penthalaris (Francischetti et al., 2004). This inhibitor harbors five tandem Kunitz domains and like Ixolaris, inhibits FVIIa/TF-induced FX activation at high concentrations by binding to the HBE of both FX and FXa.

Finally, two Ornithodoros savignyi saliva anti-coagulants have been identified: BSAP1 and BSAP2 (Ehebauer et al., 2002). These proteins do not inhibit the intrinsic pathway, whereas the extrinsic pathway appeared to have delayed clot formation. Therefore, these proteins may only target TF, as FVII does not seem to be inhibited. It may be the first time a direct TFinteracting protein has been reported, because until now the majority of known extrinsic pathway inhibitors target other factors forming complexes with TF.

\section{Intrinsic Pathway Inhibitors}

The Kunitz protein Ir-CPI was identified in I. ricinus SGs and binds to contact phase factors, FXII, FXI, and kallikrein 
(Decrem et al., 2009). In vitro experiments showed that IrCPI considerably prolonged aPTT, without modifying the extrinsic pathway, whereas experiments on both venous and arterial thrombus formation in animal models showed that IrCPI mainly inhibits clot propagation and thrombin generation (Decrem et al., 2009). Like Ixolaris, Ir-CPI does not block amidolytic activity of targeted proteases by binding to the catalytic site as is usual for Kunitz-type inhibitors, but likely acts by binding to an exosite, thereby preventing enzyme activity with high affinity steric hindrance (Laskowski and Kato, 1980).

Among the BmTIs from R. (B.) microplus tick eggs and larvae, BmTI-A strongly inhibits trypsin, hNE, plasmin and HuPK (Tanaka et al., 1999). It was initially described with two Kunitz domains, the first implicated in trypsin and HuPK inhibition and the second inhibiting hNE (Tanaka et al., 1999; Guerrero et al., 2005). Subsequently, a further five Kunitz-BPTI domains were identified (Soares et al., 2016). BmTI-A transcripts are mainly expressed in the tick midgut, and are weakly expressed in SGs and ovaries (Tanaka et al., 1999). It is possible that the inhibitor is transferred from ovaries to the larval stage where it could be important for controlling blood coagulation, inflammation, and angiogenesis during the larval feeding process, by inhibiting plasma kallikrein, neutrophil elastase, and plasmin (Tanaka et al., 1999; Soares et al., 2016).

Another Kunitz-type tSPI with a unique Kunitz domain named Rhipilin-2 was identified in Rhipicephalus hemaphysaloides, and is highly similar to members of the TFPI mammalian protein family (Cao et al., 2013). Rhipilin-2 does not prolong recalcification time in PT assays, but increases coagulation time of citrated rabbit plasma in aPTT assays. It inhibits approximately $60 \%$ of trypsin activity but does not inhibit thrombin. Rhipilin-2 gene expression was only detected in SGs and the midgut of fed ticks (Cao et al., 2013). One-day-fed ticks presented the highest expression that gradually faded until total engorgement, suggesting probable injection via saliva into the host during feeding to restrict blood clotting at the wound site (Cao et al., 2013).

Haemaphysalin, a Kunitz-type inhibitor from the hard tick $H$. longicornis also inhibits intrinsic coagulation pathways by blocking kallikrein-kinin system activation (Kato et al., 2005a,b). Its acts via its two Kunitz domains, and does not affect the amidolytic activities of intrinsic coagulation factors. Direct binding assays demonstrated binding of the $\mathrm{COOH}$-terminal domain to both high molecular weight kininogen (HMWK) and factor XII (Kato et al., 2005a,b). The COOH-terminal domain may then inhibit factor XII and HMWK association on the cell surface, and hence inhibits kallikrein-kinin system activation by interfering with prekallikrein and factor XII reciprocal activation. $\mathrm{Zn}^{2+}$ ions appear to be involved in interactions between haemaphysalin and its targets, suggesting that these cations induce conformational changes which enable haemaphysalin's inhibitory effect (Kato et al., 2005a,b).

Previously mentioned studies of DvKPI highlighted its ability to inhibit the coagulation cascade as revealed by both delayed aPTT assays and robust antitrypsin activity. Although DvKPI expression was detected in both body fat and SGs, the highest expression was in the midgut and which increased upon feeding, demonstrating that its anticoagulant activity in the midgut is essential (Ceraul et al., 2008).

\section{FX(a) Factor Inhibitors}

Tick anticoagulant protein TAP, the first tSPI to specifically inhibit FX(a) factor was identified in the soft tick Ornithodoros moubata as a Kunitz inhibitor (Waxman et al., 1990). Whereas Kunitz inhibitors are generally highly basic, TAP is acidic, and was classified as a slow, tight-binding inhibitor, because it requires at least 15 -min pre-incubation for maximal FX(a) inhibition.

Amblyomin-X was initially discovered following SG transcriptome sequencing of the Amblyomma cajennense Cayenne tick (Batista et al., 2010). This protein harbors one Kunitz-type domain, and is observed in monomeric, dimeric, trimeric, and tetrameric conformations. Amblyomin-X inhibits FXa in a non-competitive manner but also increases PT and aPTT, suggesting an effect on prothrombin conversion (Batista et al., 2010; Branco et al., 2016). Four hypotheses have been proposed to explain the FXa inhibitory mechanism of Amblyomin-X. Firstly, as Amblyomin-X shares amino acid sequence similarities with TAP, it could bind FXA as a slow, tight-binding inhibitor. The second is that the strongly negatively charged $\mathrm{COOH}$-terminal domain of Amblyomin-X could bind to positively charged FXa exosites. Thirdly, an additional binding of the Amblyomin- $\mathrm{X} \mathrm{NH}_{2}$-terminus to the FXa active site could exist. Lastly, Lys30 from the characteristic Kunitz domain loop could bind to the FXa active site (Batista et al., 2010).

The aforementioned AAS19 serpin from A. americanum also appears to be injected into the host during feeding, and enhances feeding success by inhibiting trypsin-like proteases including Fxa, hemostasis, and host immune-defenses (Kim et al., 2015, 2016).

Lastly, and despite not being fully characterized, several other FX(a) inhibitors from different tick species have been reported. Amongst these is an SG protein from the soft tick O. savignyi, with an approximate $7 \mathrm{kDa}$ molecular weight and six cysteine residues suggesting a single Kunitz domain. FXa inhibition appears specific, although thrombin was also very weakly inhibited (Gaspar et al., 1996). In Hyalomma truncatum, the bont-legged tick, several SG proteins inhibiting both extrinsic and intrinsic coagulation pathways were detected (Joubert et al., 1995). Of these, one $17 \mathrm{kDa}$ nameless protein possesses Factor Xa inhibitory activity and was only identified in females pre-fed for 5-7 days, suggesting involvement in tick feeding process. This FXa inhibition appeared to be noncompetitive, in contrast to TAP from O. moubata, but similar to another $15 \mathrm{kDa}$ tSPI identified in nymphs of the camel tick, Hyalomma dromedarii. This last tSPI totally inhibits FXa but only partially inhibits thrombin activity (30\% inhibition). Extremely efficient FXa inhibition could be explained by the presence of two binding sites on the inhibitor (Ibrahim et al., 2001b). Finally, a $65 \mathrm{kDa}$ FXa inhibitor from $R$. appendiculatus was also isolated from SG extracts (Limo et al., 1991). No complexes between FXa and this inhibitor were identified, and it was established that inhibition may occur via exosite binding. 


\section{Thrombin Inhibitors}

Crude saliva of $R$. (B.) microplus was initially investigated because of its effective bovine plasma coagulation inhibiting properties, and subsequently several thrombin inhibitors were identified. BmAP was described as a non-tight binding thrombin inhibitor, possibly dimerized, and which interacts with both thrombin active sites and subsites (Horn et al., 2000). Two microphilin isoforms were then discovered, and which are the smallest nontight binding thrombin inhibitors identified thus far (Ciprandi et al., 2006). Microphilin only interacts with thrombin at exosite I, the crucial site for both fibrinogen and platelet thrombin receptor interactions. BmGTI, from the $R$. (B.) microplus midgut, was reported to inhibit fibrinogen cleavage by thrombin (Ricci et al., 2007), via interaction with thrombin's positively charged exosite I (Monteiro, 2005). The serpin RMS-15 was identified as the highest affinity thrombin inhibitor (Rodriguez-Valle et al., 2015; Xu et al., 2016). RCT assays showed that plasma clotting time is delayed in the presence of RMS-15, in a dose-dependent manner. The elevated RMS-15 IgG titres found in bovine sera after prolonged exposure to tick infestation, and the presence of RMS-15 transcript in SGs and midgut (Rodriguez-Valle et al., 2015), suggest a likely secretion of this serpin into the tickfeeding site, which then acts on host coagulation ( $\mathrm{Xu}$ et al., 2016). Lastly, a Kunitz-type serine-protease inhibitor harboring two Kunitz domains was isolated from the tick midgut and named Boophilin (Macedo-Ribeiro et al., 2008). Boophilin greatly increases TT (Assumpção et al., 2016), significantly affects PT, and increases aPTT, albeit weakly (Macedo-Ribeiro et al., 2008). Boophilin displayed partial effects on plasma kallikrein and weak inhibitory effects on FVIIa, showing probable, but limited, implication in both extrinsic and intrinsic pathways. In addition, boophilin can block amidolytic activity of other trypsinlike serine proteases, most notably trypsin and plasmin (MacedoRibeiro et al., 2008). Boophilin is a strong thrombin inhibitor forming a stable thrombin/boophilin complex in a non-canonical manner (Macedo-Ribeiro et al., 2008). The proximal interaction between boophilin and meizothrombin (MzT) suggests that boophilin may not only target circulating thrombin but also the MzT intermediate. When boophilin and MzT are complexed, the boophilin $\mathrm{NH}_{2}$ terminus remains effectively available and able to bind proximal coagulation factors including FXa.

At the end of the nineteenth century it was demonstrated that I. ricinus saliva also contains anticoagulant molecules (Sabbatini, 1899). Ixin, a specific thrombin inhibitor, was isolated from adult saliva in 1991 (Hoffmann et al., 1991), and the serpin Iris-for "I. ricinus immunosuppressor" - was identified in 2002 (Leboulle et al., 2002b). Iris expression is induced in SGs while ticks feed, peaking at day four, coinciding with the period when the $I$. ricinus female ingests the most amount of blood. Iris demonstrates dose-dependent FXa inhibition and inhibits close to $30 \%$ of thrombin. Its inhibitory activity arises from the RCL domain where the P1 residue plays a key role, which was confirmed with Iris structural model interactions (Prevot, 2006). Iris hampers fibrinolysis by inhibiting both tissue plasminogen activator (t-PA) and elastase released by leukocytes. It also acts as a hypo-fibrinolytic factor by targeting serine proteases, especially elastase-like proteins, and appears to prevent platelet adhesion via a mechanism independent of its enzyme inhibitory activity (Prevot, 2006). However, even if Iris inhibits several serine proteases in coagulation pathways, it does not appear to be a powerful anticoagulant (Prevot, 2006).

Madanin 1 and 2 have also been identified from SGs of $H$. longicornis, as inhibiting both the intrinsic and extrinsic coagulation pathways (Iwanaga et al., 2003). Madanin proteins do not exhibit any sequence similarities with any other previously identified proteins, do harbor a signal peptide sequence, and interact with thrombin, but not with factor Xa (Iwanaga et al., 2003). Thrombin inhibition by madanins probably involves competitive binding to thrombin's fibrinogen-binding site (anion-binding exosite 1 ), and not via binding to the active site. They inhibit blood coagulation at an early stage by inhibiting thrombin activation of factors V and VIII, and thus likely contribute considerably to tick blood feeding success (Iwanaga et al., 2003). Another thrombin inhibitor named Chimadanin was identified in $H$. longicornis SGs with very weak expression. It was also detected in the hemolymph during nymphal and adult stages from the third day of blood feeding and declines until extinction on the 6th day (Nakajima et al., 2006). Lastly, Hemalin with two Kunitz domains, was identified in larval, nymphal, and adult stages, and exhibited highest expression levels during the rapid blood meal sucking period during all tick life stages (Liao et al., 2009). In addition to its role as a thrombin inhibitor, Hemalin also inhibits trypsin activity. Initially discovered in the midgut, Hemalin is also expressed in major tissues of the female tick including SGs, ovaries, hemolymph, and body fat.

In 2014, Ibelli et al. reported the presence of a new tSPI from $I$. scapularis saliva belonging to the serpin family, IxcS-1E1 (Ibelli et al., 2014). IxcS-1E1 transcript was detected both in SGs and in the midgut of ticks with a dichotomous temporal expression pattern. In SGs, expression is up-regulated from the 24 first hours of feeding, while midgut expression was down-regulated in response to feeding activity (Ibelli et al., 2014). During feeding, IxcS-1E1 is injected into the host and likely prevents platelet aggregation, as it extends clotting time both in aPTT and PT in vitro assays. It inhibits thrombin and trypsin activities by forming stable complexes, and also probably inhibits cathepsin $G$ and factor Xa enzymatic activities. Therefore IxcS-1E1 appears to be one of the most important I. scapularis saliva proteins mediating tick evasion from the host's hemostatic defense system (Ibelli et al., 2014).

In the Amblyomma genus, the Americanin protein was isolated from the SGs of A. americanum, and was shown to be a slow reversible tight-binding-type thrombin inhibitor (Zhu et al., 1997). Similar to Ixolaris and boophilin, Amblin was isolated from the synganglia of engorged $A$. hebraeum females, from where the protein is exported into the hemolymph where it can also be detected (Lai et al., 2004). Without a signal peptide and composed of two Kunitz-like domains, amblin specifically inhibits the thrombin enzyme via an unknown inhibitory mechanism. Crude SG extracts from $A$. variegatum, the tropical bont tick, also exhibited potent anticoagulant activity in the three TT, PT, and aPTT coagulation assays, thus inhibiting at least one factor implicated in the two coagulation pathways (Koh et al., 2007). The TT assay demonstrated the most significant results, 
indicating that the major targeted factor is thrombin. Variegin was then identified as a protein without any similarities to other tSPIs (Kazimírová et al., 2002). Nevertheless, its $\mathrm{NH}_{2}$-terminal sequence appears to be a fast competitive tight-binding inhibitor of thrombin. Following HPLC purification, another inhibitor with anti-thrombin effects on human blood platelets and with hirudin-like activity, was also identified from the saliva of $A$. variegatum, but has not been further characterized (Kazimírová et al., 2002).

Hard tick Hyalomma marginatum rufipes SG transcriptome investigations unearthed four peptide-encoding sequences, named hyalomins-1-4, that showed weak similarity to madanin 1 and 2 from $H$. longicornis (Francischetti et al., 2011). The central core of these polypeptides contains a weakly conserved acidic region that forms a putative serine protease cleavage site. Hyalomin-1 appears to be a specific thrombin inhibitor and noncompetitively binds to its active site, as well as an exosite I, thus significantly extending fibrin clot formation time in whole plasma (Jablonka et al., 2015). It also blocks thrombin activation of coagulation factor XI and factor V. In addition, hyalomin1 also impedes platelet aggregation by inhibiting thrombin activation of platelet proteinase activated receptor (PAR).

Two thrombin inhibitors from $H$. dromedarii nymphs were also described and named NTI-1 and NTI-2 (Ibrahim et al., 2001a). Inhibition assays revealed that NTI-1 inhibits $13 \%$ of FXa activity and $65 \%$ of thrombin activity, whereas NTI-2 inhibits $100 \%$ of FXa activity and $58 \%$ of thrombin activity, but with higher affinity for this enzyme than NTI-1. In addition, thrombin inhibition by NTI- 1 and NTI- 2 is non-competitive and competitive, respectively.

Rhipilin-1, identified in the hard tick Rhipicephalus haemaphysaloides, shares a similar conformation-a unique Kunitz domain-with other thrombin inhibitors such as boophillin, amblin, and hemalin (Gao et al., 2011). The protein, tested on rabbit citrated plasma, has the capacity to extend both RCT and aPTT in a dose-dependent manner. Both tick attachment and engorgement processes require rhipilin-1 expression, which is consistent with specific gene expression only in fed ticks (Gao et al., 2011). Two other thrombin inhibiting serpins were also identified in this tick species, serpin-1 (RHS-1) and serpin-2 (RHS-2) (Yu et al., 2013). They share similarities with other tSPIs described in this review including: RHS-1 with lopsins 1 and 2; and RHS-2 with lopsin 7 and RAS-2. Functional characterization indicated that RHS-1 is expressed in SGs of fed ticks and secreted at the tick-host interface during feeding, whereas RHS-2 is only expressed in fed tick midgut (Yu et al., 2013). Inhibition assays showed that both RHS-1 and RHS-2 mostly inhibit chymotrypsin but they also have thrombin inhibitory activity, with maximum inhibition rates of 65.5 and $20 \%$, respectively (Yu et al., 2013). For both, weak FXa inhibition was observed, and neither trypsin nor elastase was inhibited. Anticoagulation assays revealed that aPTT was prolonged in the presence of RHS-1 but not RHS-2. RNAi assays implicated both proteins in tick attachment and engorgement rates, but not in repletion time or average body weight, confirming the role of RHS-1 and RHS-2 in tick blood feeding by blocking blood coagulation (Yu et al., 2013).
Calcaratin was identified from Rhipicephalus (Boophilus) calcaratus and was able to delay coagulation time in all tests (aPTT, TT, and FCT), via an unknown thrombin inhibition mechanism (Motoyashiki et al., 2003).

Concerning soft ticks, ornithodorin was described from $O$. moubata as a thrombin inhibitor harboring two Kunitz domains (van de Locht et al., 1996). Interactions with thrombin implicate its active and exosite: the $\mathrm{NH}_{2}$-terminal domain appears to be responsible for the majority of thrombin interaction with two van-der-Waals contacts and hydrogen bonds, whereas the $\mathrm{COOH}$-terminal domain has mostly electrostatic interactions with thrombin (Klingler and Friedrich, 1997). An ornithodorin ortholog was identified in O. savignyi SGs, named savignin (Mans et al., 2002). Its $\mathrm{NH}_{2}$-terminal region seems to be implicated in binding to the thrombin active site, whereas the $\mathrm{COOH}$-terminal domain helix binds to the fibrinogen-recognition exosite domain. Savignin was then described as a slow competitive tight-binding inhibitor that binds to thrombin's fibrinogen-binding exosite for inhibition. It carries a signal peptide substantiating likely secretion during blood feeding (Mans et al., 2002). Lastly, the monobin, a slow specific tight-binding thrombin inhibitor, and an ornithodorin and savignin ortholog belonging to the Kunitz family, was also identified in Argas monolakensis (Mans et al., 2008). These three tSPIs harbor a non-canonical mechanism of action as inhibition results when their $\mathrm{NH}_{2}$-terminal residues are inserted into the enzyme active site instead of their active Kunitz loops (van de Locht et al., 1996).

Lastly, studies on salivary gland extracts from Ixodes holocyclus, the Australian paralysis tick, showed that thrombin was the main enzyme targeted by salivary anticoagulant molecules, with an uncharacterized mechanism (Anastopoulos et al., 1991).

\section{Vertebrate Host-Immune Modulation by Tick Serine Protease Inhibitors}

Because ticks are blood-feeding arthropods requiring hours to weeks to complete their blood meal, they have developed several mechanisms to evade host rejection during this long feeding period (Ribeiro, 1995; Francischetti et al., 2009; Kazimirova and Stibraniova, 2013; Kotal et al., 2015). Their saliva injected into the wound site carries many components able to manipulate vertebrate host responses, including antiinflammatory compounds as well as immunomodulators acting on both innate and acquired immunity, and among which are included several tSPIs.

In A. americanum, the aforementioned anticoagulants AamS6 and AAS19 can also target plasmin, known for its role in pro-inflammatory cytokine release, monocyte and dendritic cell chemotaxis, neutrophil attraction, tissue remodeling, and wound healing, suggesting involvement in the regulation of monocyte, macrophage, and dendritic cell functions, and in inflammatory responses (Syrovets et al., 2012). In addition, 17 different serpins called lopsins (L1-L17) were found to be expressed in various organs such as SGs, midguts, ovaries, and the carcasses of partially fed A. americanum ticks (Mulenga et al., 2007). Sequence analysis revealed the presence of glycosaminoglycan 
binding sites on all lopsins, similar to several other proteins involved in the modulation of blood coagulation, inflammatory responses, or immune cell migration (Munoz and Linhardt, 2004). However, further investigations are required to identify their inhibitory targets and to decrypt mechanisms governing lopsins' likely immunomodulatory activities.

Iris from $I$. ricinus is also a powerful immunosuppressive molecule (Leboulle et al., 2002a). It is secreted at the tick-bite site and strongly inhibits elastase-like proteases (leukocyte elastase and pancreatic elastase) with rapid kinetics, thus repressing host inflammation (Prevot, 2006). Iris regulates innate immune mechanisms by suppressing $\mathrm{T}$ lymphocyte proliferation and inducing Th2-type immune responses with increased IL-4 and by inhibiting typical Th1 molecule production (IL2, IFN- $\gamma$ ) (Leboulle et al., 2002a). IRS-2, another serpin exhibiting specific anti-chymotrypsin activity, was identified from I. ricinus SGs (Chmelar et al., 2011). In SGs, IRS-2 is highly expressed at 2 days with maximum expression 6 days after attachment, suggesting a role in the early stage of feeding. IRS-2 inhibits both tissue swelling and neutrophil migration into inflamed tissue, modulates $\mathrm{T}$ cell differentiation, and decreases IL-6 production at both protein and mRNA levels in spleen dendritic cells activated by B. burgdorferi (Chmelar et al., 2011). In addition, by decreasing STAT-3 signaling molecule phosphorylation, IRS-2 impairs Th17 cell development (Páleníková et al., 2015). IRS2 is also the only known serpin that targets both cathepsin G and chymase. Both of these proteases are secreted following neutrophil (cathepsin G) and mast cell (chymase) activation, and are involved in a huge range of physiological processes associated with the acute inflammatory response, particularly in crosstalk between neutrophils and platelets (Zarbock et al., 2007). IRS-2 also affects thrombin-induced platelet aggregation, thus likely playing multiple roles in inflammation and hemostasis particularly through the modulation of PAR activation (Chmelar et al., 2011).

The serpin Ipis-1, which shares $95.5 \%$ sequence identity with Iris, was isolated from SGs of fed Ixodes persulcatus and may be associated with immunomodulatory effects on both innate and acquired immune responses (Toyomane et al., 2016). Ipis1 may directly interact with and inhibit $\mathrm{T}$ cells and $\mathrm{CD} 14^{+}$ cells (mainly macrophages, neutrophils, and dendritic cells), with an as yet unidentified inhibitory mechanism. Similarly, Ipis-1 affects cytokine and chemokine activity via currently unknown mechanisms (Toyomane et al., 2016).

Based on previous I. scapularis sialome exploration (Ribeiro et al., 2006), a salivary Kunitz inhibitor with unusual structure was characterized and named tryptogalinin (Dai et al., 2012; Valdés et al., 2013). Tryptogalinin has a broad spectrum (potentially explained by the presence of three intrinsic disordered regions) and a high affinity for serine proteases playing an important role in inflammation and host immune responses (Heutinck et al., 2010). In fact, tryptogalinin inhibits trypsin, $\alpha$-chymotrypsin, plasmin, matriptase, elastase, and especially human skin $\beta$ tryptase found in mast cells (Valdés et al., 2013). Mast cell $\beta$-tryptase has a key role in host-inflammatory responses by stimulating chemoattractant release, such as IL8 , and by inducing IL-1 $\beta$ mRNA expression (Caughey, 2007).
Tryptogalinin causes excitation of sensory neurons and has anti-inflammatory activity by repressing tryptase-PAR type 2 activation which normally mobilizes intracellular calcium stores to increase intracellular $\mathrm{Ca}^{2+}$ concentrations (Payne and Kam, 2004).

The glycosylated Kunitz inhibitor, TdPI (tick-derived protease inhibitor), was isolated from SGs of $R$. appendiculatus adult females (Paesen et al., 2007). TdPI is only expressed during the four first hours of feeding and manipulates hostimmune defenses during the tick feeding process. TdPI potently inhibits trypsin and moderately affects human plasmin and human tryptase activity (Paesen et al., 2007). Mast cells and eosinophils initiate and/or amplify inflammation at the tick feeding site, mostly via the production and degranulation of several pro-inflammatory molecules such as histamine and tryptase. Accordingly, TdPI transcription coincides with that of RaHBPs ( $R$. appendiculatus Histamine-Binding Proteins) known to sequester histamine in ticks (Paesen et al., 1999), thus highlighting a probable role for TdPI as a human tryptase inhibitor via complex formation (Paesen et al., 2007). In addition, TdPI may bind to tryptase inside mast cells, and may suppress its autocatalytic activation step (Sakai et al., 1996).

In R. (B.) microplus, BmSI 7 inhibitor regulates bovine neutrophil elastase pro-inflammation activity, due to its strong elastase inhibitory activity. Thus by reducing inflammation and/or avoiding tick tissue degradation, it enables the tick to thwart the host immune system (Sasaki et al., 2008). Similarly, RMS-3 is likely secreted into tick saliva during feeding, and carries a B-Lymphocyte epitope, highlighting a probable role in host-immune response modulation (Rodriguez-Valle et al., 2012). Finally, 12 further proteins have been extracted from $R$. (B.) microplus larvae, initially BmTI A-F, then BmTI 1-7, among which only BmTI 2 and BmTI 3 were further characterized as follows (Sasaki et al., 2004). Both BmTIs were classified into the BPTI-Kunitz family as they are suspected to have two Kunitz domains. Both inhibit trypsin and hNE, BmTI 2 demonstrating greater trypsin inhibition, and BmTI 3 stronger hNE inhibition, suggesting a role inhibiting the host's inflammatory response (Sasaki et al., 2004).

\section{Host Angiogenesis and Apoptosis Induction}

While ticks are biting, they must control and limit wound neovascularization and cell proliferation responses to enable blood meal uptake. Thus, they inject salivary proteins to favor apoptosis and slow down neovascularization as reported for $I$. scapularis (Francischetti et al., 2005a), and interestingly, tSPIs have also been implicated in this role.

Significant similarities are shared between BmCI from R.(B.) microplus (Lima et al., 2010) and dendrotoxins. Dendrotoxins are non-inhibitory Kunitz proteins able to block different ion channels $\left(\mathrm{Na}^{+}, \mathrm{K}^{+}, \mathrm{Ca}^{+}\right)$involved in both cell proliferation (Lang et al., 2005) and apoptosis (Nutt et al., 2002). BmCI appears to be highly cytotoxic and causes fibroblast cell death via proapoptotic activity, without affecting cell cycle integrity, likely by $\mathrm{Ca}^{+}$channel activity regulation (Lima et al., 2010). 
Haemangin was identified as a salivary Kunitz inhibitor from $H$. lonigicornis carrying one single Kunitz domain, which is up-regulated during blood feeding (Islam et al., 2009). It strongly inhibits trypsin and chymotrypsin, poorly inhibits elastase, and is able to efficiently stimulate degradation of both heavy and light plasmin chains during fibrinolysis, therefore strongly supporting plasmin-dependent fibrinolysis inhibition (Islam et al., 2009). Haemangin also inhibits chick aortic explant angiogenesis; human umbilical vein endothelial cell (HUVEC) differentiation, proliferation, and tube formation; and chick ChorioAlantoic Membrane (CAMs) neovascularization, demonstrating that it can impede with both pre-existing vessel angiogenesis and neovascularization (Islam et al., 2009). Haemangin also significantly induces apoptosis in HUVECs (Nagata, 2000), and affects wound healing in an artificially wounded HUVEC monolayer (Islam et al., 2009). Anti-haemangin RNAi experiments showed that ticks completely failed to make blood pools by $72 \mathrm{~h}$ and achieved significantly diminished engorgement by $144 \mathrm{~h}$, while control ticks become engorged by $120 \mathrm{~h}$, with the simultaneous increase of neovascularization in knockdown ticks (Islam et al., 2009). High-throughput studies also indicated that Haemangin can utilize multiple intracellular signaling pathways to negatively regulate angiogenesis, and angiogenesis-dependent wound healing (Islam et al., 2009). Interestingly, it was noticed that soft ticks-which are fast blood-feeders compared to hard tick-lack Haemangin homologs, thereby highlighting the importance of these molecules during the long blood feeding processes of hard ticks (Francischetti et al., 2005a).

BmTI-A from $R$. (B.) microplus also strongly inhibits neovascularization, and prevents new vessel formation in vitro by inhibiting plasma kallikrein, plasmin, and elastase (Soares et al., 2016). In addition, BmTI-A inhibits endothelial cell viability and proliferation through kallikrein inhibition (Lang et al., 2005), leading to an absence of bradykinin release, which normally stimulates cell growth and survival (Andoh et al., 2010). The inhibition of plasma kallikrein and plasmin by BmTI-A prevents angiogenic growth factor release during tick infestation, thereby averting cell adhesion mechanisms (Soares et al., 2016). Neutrophil elastase degrades a broad spectrum of extracellular matrix and cell surface proteins, and the release of growth factors such as TGF- $\beta$, PDGF, and VEGF, induces cell proliferation and migration. By inhibiting neutrophil elastase, BmTI-A could also inhibit angiogenesis (Wada et al., 2007). BmTI-A is also believed to have an inhibitory action on both vessel formation and wound healing, thus enabling $R$. (B.) microplus to continue feeding (Soares et al., 2012).

Finally, the anticoagulant Amblyomin-X from A. cajennense can also act as a proteasome inhibitor (Chudzinski-Tavassi et al., 2010). Amblyomin-X demonstrates cytotoxicity in different tumor cells lines, but not in healthy human fibroblast cells (Chudzinski-Tavassi et al., 2010; Morais et al., 2016). In human tumor cells, Amblyomin-X alters the expression of several genes related to the cell cycle (related to the G0/G1 phase, as supported by observed G0/G1 alterations), causes endoplasmic reticulum stress marker accumulation, slightly modulates intracellular calcium concentration $\left[\mathrm{Ca} 2^{+}\right]$, causes mitochondrial dysfunction, cytochrome $\mathrm{C}$ release, poly (ADPribose) polymerase (PARP) cleavage, and activates the caspase cascade (Chudzinski-Tavassi et al., 2010; Morais et al., 2016). Additional in vitro assays on endothelial cells showed that Amblyomin-X delays the cell cycle, inhibits cell proliferation and adhesion, tube formation, and membrane expression of the platelet-endothelial cell adhesion molecule-1 (PECAM1) (Drewes et al., 2012). In vivo, Amblyomin- $X$ reduces tumoral mass in a murine melanoma model, decreases the number of metastatic events (Chudzinski-Tavassi et al., 2010), and also inhibits VEGF-A-induced angiogenesis in the dorsal subcutaneous tissue in mice (Drewes et al., 2012). Similar effects were observed in chicken chorioallantoic membrane (CAM). These investigations confirm the anti-tumorigenic and antiangiogenic properties of Amblyomin-X.

\section{SERINE PROTEASE INHIBITORS INVOLVED IN TICK-BORNE PATHOGEN DEVELOPMENT AND TRANSMISSION}

During tick feeding, all the above-mentioned molecules modulating host immune responses and homeostasis create an environment conducive to pathogen transmission and host infection (Brossard and Wikel, 2004; Nuttall and Labuda, 2004; Ramamoorthi et al., 2005; Wikel, 2013). Several tick molecules directly implicated in pathogen transmission have also been identified. They either facilitate pathogen development in the tick vector, or enhance pathogen transmission to the vertebrate host (Liu and Bonnet, 2014). Among them, a few tSPIs have been shown to affect pathogen development and/or transmission (Figure 2, Table 2) but, in all cases, the precise mechanisms involved remain unknown.

Two-dimensional electrophoresis of total proteins from fully engorged R. (B.) microplus adults revealed BmTI-A up-regulation in $B$. bovis-infected ticks. This differential expression suggests a putative role for this protein in the tick's immune system, to either limit the potentially detrimental proliferation of the parasite in the vector, or as a molecule required for parasite development and/or colonization of tick tissues (Rachinsky et al., 2007). It is noticeable that the expression of BmTI-A in tick ovaries is coherent with the vertically transmission that occurs for this parasite from the female to the next generation.

DvKPI from $D$. variabilis reduces burden of the obligate intracellular bacteria $R$. montanensis at $24 \mathrm{~h}$ post-infection in L929 mouse fibroblasts in vitro (Ceraul et al., 2008), and associations between the inhibitor and the bacteria have been reported, thus it was hypothesized that bacteria may express trypsin-like proteases on their outer surface (Ceraul et al., 2011). Alternatively, DvKPI may be implicated in recruiting host factors, such as plasminogen activation system factors facilitating midgut epithelium transmigration, as has been demonstrated for B. burgdorferi (Coleman et al., 1997). Therefore DvKPI might be involved in both the tick immune system and in Rickettsia development (Walker et al., 1984).

In I. ricinus, a comparison of Bartonella henselae-infected or non-infected SG transcriptomes led to the discovery of IrSPI 
(Ixodes ricinus serine protease inhibitor), a Kunitz inhibitor with the highest expression following bacterial infection (Liu et al., 2014). It was demonstrated that $B$. henselae, a facultative intracellular bacterium responsible for cat-scratch disease, can be transmitted by $I$. ricinus through the injection of saliva (Cotté et al., 2008). RNAi experiments showed that when IrSPI expression was significantly knocked down, both the weight of engorged ticks and $B$. henselae SG load were significantly decreased, suggesting IrSPI involvement in blood feeding, as well as in SG bacterial development (Liu et al., 2014).

Lastly, Lyme disease caused by bacteria from the Borrelia genus is unquestionably the predominant concern for the Northern latitude (Dantas-Torres et al., 2012) and several studies concern their transmission by tick from the Ixodes genus. Ixophilin-immunized mouse assays showed that despite no effects on Borrelia burgdorferi burden in I. scapularis tick midgut, significantly increased $B$. burgdorferi burden in the skin, heart, and bladder of immunized mice was observed, suggesting a probable role in B. burgdorferi transmission to and/or development in the host (Narasimhan et al., 2013).

\section{APPLICATIONS IN TICK CONTROL}

To date, acaricides are mainly used to control ticks. But their use has several detrimental effects, including a negative impact on the environment and non-targeted species, as well as an associated rise in resistant tick strains. Thus new effective control measures are urgently required, such as anti-tick vaccines. Vaccines that target important molecules implicated in tick feeding processes and physiology could decrease tick populations and limit transmission of a vast number of pathogens. This is the manner in which the only two commercially-available anti-tick vaccines-based on an $R$. (B.) microplus midgut protein-are believed to function (Kemp et al., 1989). By targeting tick molecules implicated in pathogen establishment, development and transmission, vaccines could also completely impair pathogen transmission.

Several tSPIs have been investigated as possible targets to create anti-tick vaccines. First, a combination of RAS-1 and -2 $R$. appendiculatus serpins was tested on cattle (Imamura et al., 2006). Results showed that the cumulative number of engorged nymphs and adults fed on vaccinated cattle was significantly lower compared to controls, tick mortality rates were significantly higher, and eggs masses from females were lower. But for ticks that did feed, feeding duration as well as engorgement weight did not differ between the two tick groups.

BmTIs from R. (B.) microplus have also been used in cattle immunization assays. A reduction in the total number of engorged ticks was observed (72.8\%), as well as reduced engorged female weight in vaccinated animals comparing to controls (Andreotti et al., 2002).

The Serpin-1 (HLS-1) from H. longicornis was also evaluated as a vaccine candidate against tick infestation (Sugino et al., 2003). No differences in feeding duration or engorgement weight between vaccinated rabbits and controls groups were observed, but a significant increase in tick mortality rates was reported for ticks fed on vaccinated animals. As rabbit antitick immunity compromised tick physiology of both nymphs and adults, these promising results support HLS-1 as a vaccine cocktail component, along with other previously characterized antigens (Mulenga et al., 1999; Tsuda et al., 2001).

Another trypsin inhibitor from $R$. (B). microplus was recently identified due to its homology with BmTI. Named RmLTI-for $R$. (B.) microplus larval trypsin inhibitor-it belongs to the Kunitz inhibitor family (Guerrero et al., 2005; Andreotti et al., 2012). RmLTI's role is completely unknown, but due to encouraging results reported for BmTIs, RmLTI's potential as a vaccine antigen was also tested in cattle. Vaccination with recombinant RmLTI showed that the average weight of engorged ticks was significantly lower after feeding on vaccinated cattle for up to 9 days after vaccination, but then remained equivalent from days 9-13, probably due to declining antibody levels (Andreotti et al., 2012). However, ticks detaching from RmLTI-immunized cattle still appeared to be affected at day 13 , and while no differences were observed in egg laying, significant effects were observed on egg viability, eclosion rate, as well as larval hatchability (Andreotti et al., 2012).

\section{CONCLUSION}

The goal of this review was to comprehensively describe the varied roles of tSPIs in both tick physiology and vertebrate host response modulation following tick bite, emphasizing their vital roles in tick-host-pathogen interactions. tSPIs are thus involved in essential processes such as tick's innate immune system and hemolymph clotting. In addition, some tSPIs expressed in ovaries and eggs are essential for tick development, oviposition and egg laying. Some ovary-expressed inhibitors are also utilized by eggs to avoid self-proteolysis and protection against foreign microorganisms. Ticks have been obligatory blood feeding arthropods for more than 90 million years, as such, they've developed and adapted appropriate molecules to facilitate their extremely efficient feeding processes. Several tSPIs are implicated in blood uptake and digestion in the tick midgut, SGs, and at the wound feeding pool on the host. In addition to immunomodulation and angiogenesis suppression, most tSPIs inhibit blood coagulation, often via FXa and thrombin targeting, enabling effective blood intake. Some tSPIs have also been reported to be involved in direct pathogen establishment and/or transmission, and also by creating opportune conditions to facilitate pathogen transmission from ticks to hosts. Such a wide spectrum of actions ensures that tSPIs are attractive and promising target candidates in anti-tick vaccine strategies to block tick feeding and/or TBP transmission.

\section{AUTHOR CONTRIBUTIONS}

$\mathrm{AB}$ and $\mathrm{SB}$ conducted the literature research and prepared the figures and tables. $\mathrm{SB}, \mathrm{AB}$, and $\mathrm{TF}$ wrote the paper, provided critical review, and revisions.

\section{ACKNOWLEDGMENTS}

We thank members of the "Tiques et Maladies à Tiques" group (REID-Réseau Ecologie des Interactions Durables) for fruitful discussions. 


\section{REFERENCES}

Abreu, P. A., Soares, T. S., Buarque, D. S., Torquato, R. S., and Tanaka, A. S. (2014). RmKK, a tissue kallikrein inhibitor from Rhipicephalus microplus eggs. Biochem. Biophys. Res. Commun. 449, 69-73. doi: 10.1016/j.bbrc.2014.04.154

Adakal, H., Stachurski, F., and Chevillon, C. (2013). Tick control practices in Burkina Faso and acaricide resistance survey in Rhipicephalus (Boophilus) geigyi (Acari: Ixodidae). Exp. Appl. Acarol. 59, 483-491. doi: 10.1007/s10493-012-9610-5

Aird, W. C. (2003). Hemostasis and irreducible complexity. J. Thromb. Haemost. 1, 227-230. doi: 10.1046/j.1538-7836.2003.00062.x

Alim, M. A., Islam, M. K., Anisuzzaman, Miyoshi, T., Hatta, T., Yamaji, K., et al. (2012). A hemocyte-derived Kunitz-BPTI-type chymotrypsin inhibitor, HlChI, from the Ixodid tick Haemaphysalis longicornis, plays regulatory functions in tick blood-feeding processes. Insect Biochem. Mol. Biol. 42, 925-934. doi: 10.1016/j.ibmb.2012.09.005

Anastopoulos, P., Thurn, M. J., and Broady, K. W. (1991). Anticoagulant in the tick Ixodes holocyclus. Aust. Vet. J. 68, 366-367. doi: 10.1111/j.1751-0813.1991.tb00740.x

Anderson, J. M., Sonenshine, D. E., and Valenzuela, J. G. (2008). Exploring the mialome of ticks: an annotated catalogue of midgut transcripts from the hard tick, Dermacentor variabilis (Acari: Ixodidae). BMC Genomics 9:552. doi: 10.1186/1471-2164-9-552

Andoh, T., Akira, A., Saiki, I., and Kuraishi, Y. (2010). Bradykinin increases the secretion and expression of endothelin-1 through kinin B2 receptors in melanoma cells. Peptides 31, 238-241. doi: 10.1016/j.peptides.2009.12.003

Andreotti, R., Cunha, R. C., Soares, M. A., Guerrero, F. D., Leivas Leite, F. P., and Pérez de León, A. A. (2012). Protective immunity against tick infestation in cattle vaccinated with recombinant trypsin inhibitor of Rhipicephalus microplus. Vaccine 30, 6678-6685. doi: 10.1016/j.vaccine.2012.08.066

Andreotti, R., Gomes, A., Malavazi-Piza, K. C., Sasaki, S. D., Sampaio, C. A., and Tanaka, A. S. (2002). BmTI antigens induce a bovine protective immune response against Boophilus microplus tick. Int. Immunopharmacol. 2, 557-563. doi: 10.1016/S1567-5769(01)00203-X

Andreotti, R., Malavazi-Piza, K. C., Sasaki, S. D., Torquato, R. J., Gomes, A., and Tanaka, A. S. (2001). Serine proteinase inhibitors from eggs and larvae of tick Boophilus microplus: purification and biochemical characterization. J. Protein Chem. 20, 337-343. doi: 10.1023/A:1012242817869

Armstrong, P. B., Rossner, M. T., and Quigley, J. P. (1985). An alpha 2macroglobulinlike activity in the blood of chelicerate and mandibulate arthropods. J. Exp. Zool. 236, 1-9. doi: 10.1002/jez.1402360102

Ascenzi, P., Bocedi, A., Bolognesi, M., Spallarossa, A., Coletta, M., De Cristofaro, R., et al. (2003). The bovine basic pancreatic trypsin inhibitor (Kunitz inhibitor): a milestone protein. Curr. Protein Pept. Sci. 4, 231-251. doi: 10.2174/1389203033487180

Assumpção, T. C., Ma, D., Mizurini, D. M., Kini, R. M., Ribeiro, J. M. C., Kotsyfakis, M., et al. (2016). In vitro mode of action and anti-thrombotic activity of boophilin, a multifunctional kunitz protease inhibitor from the midgut of a tick vector of Babesiosis, Rhipicephalus microplus. PLoS Negl. Trop. Dis. 10:e0004298. doi: 10.1371/journal.pntd.0004298

Batista, I. F., Ramos, O. H., Ventura, J. S., Junqueira-de-Azevedo, I. L., Ho, P. L., and Chudzinski-Tavassi, A. M. (2010). A new factor Xa inhibitor from Amblyomma cajennense with a unique domain composition. Arch. Biochem. Biophys. 493, 151-156. doi: 10.1016/j.abb.2009.10.009

Bissinger, B. W., Donohue, K. V., Khalil, S. M., Grozinger, C. M., Sonenshine, D. E., Zhu, J., et al. (2011). Synganglion transcriptome and developmental global gene expression in adult females of the American dog tick, Dermacentor variabilis (Acari: Ixodidae). Insect Mol. Biol. 20, 465-491. doi: 10.1111/j.1365-2583.2011.01086.x

Branco, V. G., Iqbal, A., Alvarez-Flores, M. P., Sciani, J. M., de Andrade, S. A., Iwai, L. K., et al. (2016). Amblyomin-X having a Kunitz-type homologous domain, is a noncompetitive inhibitor of FXa and induces anticoagulation in vitro and in vivo. Biochim. Biophys. Acta 1864, 1428-1435. doi: 10.1016/j.bbapap.2016.07.011

Brossard, M., and Wikel, S. K. (2004). Tick immunobiology. Parasitology 129(Suppl.), S161-S176. doi: 10.1017/S0031182004004834

Buresová, V., Franta, Z., and Kopácek, P. (2006). A comparison of Chryseobacterium indologenes pathogenicity to the soft tick Ornithodoros moubata and hard tick Ixodes ricinus. J. Invertebr. Pathol. 93, 96-104. doi: 10.1016/j.jip.2006.05.006

Buresova, V., Hajdusek, O., Franta, Z., Sojka, D., and Kopacek, P. (2009). IrAMan $\alpha 2$-macroglobulin from the hard tick Ixodes ricinus: characterization and function in phagocytosis of a potential pathogen Chryseobacterium indologenes. Dev. Comp. Immunol. 33, 489-498. doi: 10.1016/j.dci.2008.09.011

Cao, J., Shi, L., Zhou, Y., Gao, X., Zhang, H., Gong, H., et al. (2013). Characterization of a new Kunitz-type serine protease inhibitor from the hard tick Rhipicephalus hemaphysaloides. Arch. Insect Biochem. Physiol. 84, 104-113. doi: 10.1002/arch.21118

Caughey, G. H. (2007). Mast cell tryptases and chymases in inflammation and host defense. Immunol. Rev. 217, 141-154. doi: 10.1111/j.1600-065X.2007.00509.x

Ceraul, S. M., Chung, A., Sears, K. T., Popov, V. L., Beier-Sexton, M., Rahman, M. S., et al. (2011). A Kunitz protease inhibitor from Dermacentor variabilis, a vector for spotted fever group rickettsiae, limits Rickettsia montanensis invasion. Infect. Immun. 79, 321-329. doi: 10.1128/IAI.00362-10

Ceraul, S. M., Dreher-Lesnick, S. M., Gillespie, J. J., Rahman, M. S., and Azad, A. F. (2007). New tick defensin isoform and antimicrobial gene expression in response to Rickettsia montanensis challenge. Infect. Immun. 75, 1973-1983. doi: 10.1128/IAI.01815-06

Ceraul, S. M., Dreher-Lesnick, S. M., Mulenga, A., Rahman, M. S., and Azad, A. F. (2008). Functional characterization and novel rickettsiostatic effects of a Kunitz-type serine protease inhibitor from the tick Dermacentor variabilis. Infect. Immun. 76, 5429-5435. doi: 10.1128/IAI.00866-08

Cerenius, L., Liu, H., Zhang, Y., Rimphanitchayakit, V., Tassanakajon, A., Gunnar Andersson, M., et al. (2010). High sequence variability among hemocytespecific Kazal-type proteinase inhibitors in decapod crustaceans. Dev. Comp. Immunol. 34, 69-75. doi: 10.1016/j.dci.2009.08.005

Chalaire, K. C., Kim, T. K., Garcia-Rodriguez, H., and Mulenga, A. (2011). Amblyomma americanum (L.) (Acari: Ixodidae) tick salivary gland serine protease inhibitor (serpin) 6 is secreted into tick saliva during tick feeding. J. Exp. Biol. 214, 665-673. doi: 10.1242/jeb.052076

Chand, H. S., Schmidt, A. E., Bajaj, S. P., and Kisiel, W. (2004). Structurefunction analysis of the reactive site in the first Kunitz-type domain of human tissue factor pathway inhibitor-2. J. Biol. Chem. 279, 17500-17507. doi: 10.1074/jbc.M400802200

Chmelar, J., Kotal, J., Karim, S., Kopacek, P., Francischetti, I. M., Pedra, J. H., et al. (2016). Sialomes and mialomes: a systems-biology view of tick tissues and tickhost interactions. Trends Parasitol. 32, 242-254. doi: 10.1016/j.pt.2015.10.002

Chmelar, J., Oliveira, C. J., Rezacova, P., Francischetti, I. M. B., Kovarova, Z., Pejler, G., et al. (2011). A tick salivary protein targets cathepsin G and chymase and inhibits host inflammation and platelet aggregation. Blood 117, 736-744. doi: 10.1182/blood-2010-06-293241

Chudzinski-Tavassi, A. M., De-Sá-Júnior, P. L., Simons, S. M., Maria, D. A., de Souza Ventura, J., de Fátima Correia Batista, I., et al. (2010). A new tick Kunitztype inhibitor, amblyomin-X, induces tumor cell death by modulating genes related to the cell cycle and targeting the ubiquitin-proteasome system. Toxicon 56, 1145-1154. doi: 10.1016/j.toxicon.2010.04.019

Ciprandi, A., de Oliveira, S. K., Masuda, A., Horn, F., and Termignoni, C. (2006). Boophilus microplus: its saliva contains microphilin, a small thrombin inhibitor. Exp. Parasitol. 114, 40-46. doi: 10.1016/j.exppara.2006.02.010

Coleman, J. L., Gebbia, J. A., Piesman, J., Degen, J. L., Bugge, T. H., and Benach, J. L. (1997). Plasminogen is required for efficient dissemination of B. burgdorferi in ticks and for enhancement of spirochetemia in mice. Cell 89, 1111-1119. doi: 10.1016/S0092-8674(00)80298-6

Cotté, V., Bonnet, S., Le Rhun, D., Le Naour, E., Chauvin, A., Boulouis, H. J., et al. (2008). Transmission of Bartonella henselae by Ixodes ricinus. Emerging Infect. Dis. 14, 1074-1080. doi: 10.3201/eid1407.071110

Cotté, V., Sabatier, L., Schnell, G., Carmi-Leroy, A., Rousselle, J. C., Arsene-Ploetze, F., et al. (2014). Differential expression of Ixodes ricinus salivary gland proteins in the presence of the Borrelia burgdorferi sensu lato complex. J. Proteomics 96, 29-43. doi: 10.1016/j.jprot.2013.10.033

Creighton, T. E. (1975). The two-disulphide intermediates and the folding pathway of reduced pancreatic trypsin inhibitor. J. Mol. Biol. 95, 167-199. doi: 10.1016/0022-2836(75)90389-7

Dai, S.-X., Zhang, A.-D., and Huang, J.-F. (2012). Evolution, expansion and expression of the Kunitz/BPTI gene family associated with long-term blood feeding in Ixodes scapularis. BMC Evol. Biol. 12:4. doi: 10.1186/1471-2148-12-4 
Dantas-Torres, F., Chomel, B. B., and Otranto, D. (2012). Ticks and tickborne diseases: a One Health perspective. Trends Parasitol. 28, 437-446. doi: 10.1016/j.pt.2012.07.003

Decrem, Y., Rath, G., Blasioli, V., Cauchie, P., Robert, S., Beaufays, J., et al. (2009). Ir-CPI, a coagulation contact phase inhibitor from the tick Ixodes ricinus, inhibits thrombus formation without impairing hemostasis. J. Exp. Med. 206, 2381-2395. doi: 10.1084/jem.20091007

De Meneghi, D., Stachurski, F., and Adakal, H. (2016). Experiences in tick control by Acaricide in the traditional cattle sector in Zambia and Burkina Faso: possible environmental and public health implications. Front Public Health 4:239. doi: 10.3389/fpubh.2016.00239

Drewes, C. C., Dias, R. Y. S., Hebeda, C. B., Simons, S. M., Barreto, S. A., Ferreira, J. M., et al. (2012). Actions of the Kunitz-type serine protease inhibitor amblyomin-X on VEGF-A-induced angiogenesis. Toxicon 60, 333-340. doi: 10.1016/j.toxicon.2012.04.349

Egekwu, N., Sonenshine, D. E., Bissinger, B. W., and Roe, R. M. (2014). Transcriptome of the female synganglion of the black-legged tick Ixodes scapularis (Acari: Ixodidae) with comparison between Illumina and 454 systems. PLoS ONE 9:e102667. doi: 10.1371/journal.pone.0102667

Ehebauer, M. T., Mans, B. J., Gaspar, A. R., and Neitz, A. W. (2002). Identification of extrinsic blood coagulation pathway inhibitors from the tick Ornithodoros savignyi (Acari: Argasidae). Exp. Parasitol. 101, 138-148. doi: 10.1016/S0014-4894(02)00102-9

Fogaça, A. C., Almeida, I. C., Eberlin, M. N., Tanaka, A. S., Bulet, P., and Daffre, S. (2006). Ixodidin, a novel antimicrobial peptide from the hemocytes of the cattle tick Boophilus microplus with inhibitory activity against serine proteinases. Peptides 27, 667-674. doi: 10.1016/j.peptides.2005.07.013

Francischetti, I. M. B., Anderson, J. M., Manoukis, N., Pham, V. M., and Ribeiro, J. M. C. (2011). An insight into the sialotranscriptome and proteome of the coarse bontlegged tick, Hyalomma marginatum rufipes. J. Proteomics 74, 2892-2908. doi: 10.1016/j.jprot.2011.07.015

Francischetti, I. M. B., Mather, T. N., and Ribeiro, J. M. C. (2005a). Tick saliva is a potent inhibitor of endothelial cell proliferation and angiogenesis. Thromb. Haemost. 94, 167. doi: 1160/th04-09-0566

Francischetti, I. M., Mather, T. N., and Ribeiro, J. M. (2004). Penthalaris, a novel recombinant five-Kunitz tissue factor pathway inhibitor (TFPI) from the salivary gland of the tick vector of Lyme disease, Ixodes scapularis. Thromb. Haemost. 91, 886-898. doi: 10.1160/TH03-11-0715

Francischetti, I. M., My Pham, V., Mans, B. J., Andersen, J. F., Mather, T. N., Lane, R. S., et al. (2005b). The transcriptome of the salivary glands of the female western black-legged tick Ixodes pacificus (Acari: Ixodidae). Insect Biochem. Mol. Biol. 35, 1142-1161. doi: 10.1016/j.ibmb.2005.05.007

Francischetti, I. M., Sa-Nunes, A., Mans, B. J., Santos, I. M., and Ribeiro, J. M. (2009). The role of saliva in tick feeding. Front. Biosci. 14, 2051-2088. doi: $10.2741 / 3363$

Francischetti, I. M., Valenzuela, J. G., Andersen, J. F., Mather, T. N., and Ribeiro, J. M. (2002). Ixolaris, a novel recombinant tissue factor pathway inhibitor (TFPI) from the salivary gland of the tick, Ixodes scapularis: identification of factor X and factor Xa as scaffolds for the inhibition of factor VIIa/tissue factor complex. Blood 99, 3602-3612. doi: 10.1182/blood-2001-12-0237

Franta, Z., Frantova, H., Konvickova, J., Horn, M., Sojka, D., Mares, M., et al. (2010). Dynamics of digestive proteolytic system during blood feeding of the hard tick Ixodes ricinus. Parasit. Vectors 3:119. doi: 10.1186/1756-3305-3-119

Fredslund, F., Laursen, N. S., Roversi, P., Jenner, L., Oliveira, C. L., Pedersen, J. S., et al. (2008). Structure of and influence of a tick complement inhibitor on human complement component 5. Nat. Immunol. 9, 753-760. doi: $10.1038 /$ ni. 1625

Gao, X., Shi, L., Zhou, Y., Cao, J., Zhang, H., and Zhou, J. (2011). Characterization of the anticoagulant protein Rhipilin-1 from the Rhipicephalus haemaphysaloides tick. J. Insect Physiol. 57, 339-343. doi: 10.1016/j.jinsphys.2010.12.001

Garcia, G. R., Gardinassi, L. G., Ribeiro, J. M., Anatriello, E., Ferreira, B. R., Moreira, H. N., et al. (2014). The sialotranscriptome of Amblyomma triste, Amblyomma parvum and Amblyomma cajennense ticks, uncovered by 454based RNA-seq. Parasit. Vectors 7:430. doi: 10.1186/1756-3305-7-430

Gaspar, A., Joubert, A. M., Crause, J. C., and Neitz, A. W. H. (1996). Isolation and characterization of an anticoagulant from the salivary glands of the tick, Ornithodoros savignyi (Acari: Argasidae). Exp. Appl. Acarol. 20, 583-598.
Grzesiak, A., Helland, R., Smalas, A. O., Krowarsch, D., Dadlez, M., and Otlewski, J. (2000). Substitutions at the P(1) position in BPTI strongly affect the association energy with serine proteinases. J. Mol. Biol. 301, 205-217. doi: 10.1006/jmbi.2000.3935

Gubb, D., Sanz-Parra, A., Barcena, L., Troxler, L., and Fullaondo, A. (2010). Protease inhibitors and proteolytic signalling cascades in insects. Biochimie 92, 1749-1759. doi: 10.1016/j.biochi.2010.09.004

Gudderra, N. P., Sonenshine, D. E., Apperson, C. S., and Roe, R. M. (2002). Hemolymph proteins in ticks. J. Insect Physiol. 48, 269-278. doi: 10.1016/S0022-1910(02)00050-1

Guerrero, F. D., Miller, R. J., Rousseau, M. E., Sunkara, S., Quackenbush, J., Lee, Y., et al. (2005). BmiGI: a database of cDNAs expressed in Boophilus microplus, the tropical/southern cattle tick. Insect Biochem. Mol. Biol. 35, 585-595. doi: 10.1016/j.ibmb.2005.01.020

Hajdusek, O., Sima, R., Ayllon, N., Jalovecka, M., Perner, J., de la Fuente, J., et al. (2013). Interaction of the tick immune system with transmitted pathogens. Front. Cell. Infect. Microbiol. 3:26. doi: 10.3389/fcimb.2013.00026

Heutinck, K. M., ten Berge, I. J. M., Hack, C. E., Hamann, J., and Rowshani, A. T. (2010). Serine proteases of the human immune system in health and disease. Mol. Immunol. 47, 1943-1955. doi: 10.1016/j.molimm.2010.04.020

Hoffmann, A., Walsmann, P., Riesener, G., Paintz, M., and Markwardt, F. (1991). Isolation and characterization of a thrombin inhibitor from the tick Ixodes ricinus. Pharmazie 46, 209-212.

Horn, F., Coutinho dos Santos, P. C., and Termignoni, C. (2000). Boophilus microplus anticoagulant protein: an antithrombin inhibitor isolated from the cattle tick saliva. Arch. Biochem. Biophys. 384, 68-73. doi: 10.1006/abbi.2000.2076

Huntington, J. A. (2011). Serpin structure, function and dysfunction. J. Thromb. Haemost. 9(Suppl. 1), 26-34. doi: 10.1111/j.1538-7836.2011.04360.x

Huntington, J. A., Read, R. J., and Carrell, R. W. (2000). Structure of a serpinprotease complex shows inhibition by deformation. Nature 407, 923-926. doi: $10.1038 / 35038119$

Ibelli, A. M. G., Kim, T. K., Hill, C. C., Lewis, L. A., Bakshi, M., Miller, S., et al. (2014). A blood meal-induced Ixodes scapularis tick saliva serpin inhibits trypsin and thrombin, and interferes with platelet aggregation and blood clotting. Int. J. Parasitol. 44, 369-379. doi: 10.1016/j.ijpara.2014.01.010

Ibrahim, M. A., Ghazy, A.-H., Maharem, T., and Khalil, M. (2001a). Isolation and properties of two forms of thrombin inhibitor from the nymphs of the camel tick Hyalomma dromedarii (Acari: Ixodidae). Exp. Appl. Acarol. 25, 675-698. doi: 10.1023/A:1016136207308

Ibrahim, M. A., Ghazy, A. H., Maharem, T. M., and Khalil, M. I. (2001b). Factor $\mathrm{Xa}$ (FXa) inhibitor from the nymphs of the camel tick Hyalomma dromedarii. Comp. Biochem. Physiol. B Biochem. Mol. Biol. 130, 501-512. doi: 10.1016/S1096-4959(01)00459-6

Imamura, S., da Silva Vaz Junior, I., Sugino, M., Ohashi, K., and Onuma, M. (2005). A serine protease inhibitor (serpin) from Haemaphysalis longicornis as an anti-tick vaccine. Vaccine 23, 1301-1311. doi: 10.1016/j.vaccine.2004.08.041

Imamura, S., Namangala, B., Tajima, T., Tembo, M. E., Yasuda, J., Ohashi, K., et al. (2006). Two serine protease inhibitors (serpins) that induce a bovine protective immune response against Rhipicephalus appendiculatus ticks. Vaccine 24, 2230-2237. doi: 10.1016/j.vaccine.2005.10.055

Irving, J. A., Pike, R. N., Dai, W., Bromme, D., Worrall, D. M., Silverman, G. A., et al. (2002). Evidence that serpin architecture intrinsically supports papainlike cysteine protease inhibition: engineering alpha(1)-antitrypsin to inhibit cathepsin proteases. Biochemistry 41, 4998-5004. doi: 10.1021/bi0159985

Islam, M. K., Tsuji, N., Miyoshi, T., Alim, M. A., Huang, X., Hatta, T., et al. (2009). The Kunitz-like modulatory protein haemangin is vital for hard tick bloodfeeding success. PLoS Pathog. 5:e1000497. doi: 10.1371/journal.ppat.1000497

Iwanaga, S., Okada, M., Isawa, H., Morita, A., Yuda, M., and Chinzei, Y. (2003). Identification and characterization of novel salivary thrombin inhibitors from the ixodidae tick, Haemaphysalis longicornis. Eur. J. Biochem. 270, 1926-1934. doi: 10.1046/j.1432-1033.2003.03560.x

Jablonka, W., Kotsyfakis, M., Mizurini, D. M., Monteiro, R. Q., Lukszo, J., Drake, S. K., et al. (2015). Identification and mechanistic analysis of a novel tick-derived inhibitor of thrombin. PLOS ONE 10:e0133991. doi: 10.1371/journal.pone.0133991

Joubert, A. M., Crause, J. C., Gaspar, A., Clarke, F. C., Spickett, A. M., and Neitz, A. W. H. (1995). Isolation and characterization of an anticoagulant present in 
the salivary glands of the bont-legged tick, Hyalomma truncatum. Exp. Appl. Acarol. 19, 79-92. doi: 10.1007/BF00052548

Kato, N., Iwanaga, S., Okayama, T., Isawa, H., Yuda, M., and Chinzei, Y. (2005a). Identification and characterization of the plasma kallikrein-kinin system inhibitor, haemaphysalin, from hard tick, Haemaphysalis longicornis. Thromb. Haemost. 93, 359-367. doi: 10.1160/TH04-05-0319

Kato, N., Okayama, T., Isawa, H., Yuda, M., Chinzei, Y., and Iwanaga, S. (2005b). Contribution of the $\mathrm{N}$-terminal and C-terminal domains of haemaphysalin to inhibition of activation of plasma kallikrein-kinin system. J. Biochem. 138, 225-235. doi: 10.1093/jb/mvi123

Kazimírová, M., Jancinová, V., Petríková, M., Takác, P., Labuda, M., and Nosál, R. (2002). An inhibitor of thrombin-stimulated blood platelet aggregation from the salivary glands of the hard tick Amblyomma variegatum (Acari: Ixodidae). Exp. Appl. Acarol. 28, 97-105. doi: 10.1023/A:1025398 100044

Kazimirova, M., and Stibraniova, I. (2013). Tick salivary compounds: their role in modulation of host defences and pathogen transmission. Front. Cell. Infect. Microbiol. 3:43. doi: 10.3389/fcimb.2013.00043

Keller, P. M., Waxman, L., Arnold, B. A., Schultz, L. D., Condra, C., and Connolly, T. M. (1993). Cloning of the cDNA and expression of moubatin, an inhibitor of platelet aggregation. J. Biol. Chem. 268, 5450-5456.

Kemp, D. H., Pearson, R. D., Gough, J. M., and Willadsen, P. (1989). Vaccination against Boophilus microplus: localization of antigens on tick gut cells and their interaction with the host immune system. Exp. Appl. Acarol. 7, 43-58. doi: 10.1007/BF01200452

Khan, M. S., Singh, P., Azhar, A., Naseem, A., Rashid, Q., Kabir, M. A., et al. (2011). Serpin inhibition mechanism: a delicate balance between native metastable state and polymerization. J. Amino Acids 2011:606797. doi: 10.4061/2011/606797

Kim, T. K., Radulovic, Z., and Mulenga, A. (2016). Target validation of highly conserved Amblyomma americanum tick saliva serine protease inhibitor 19. Ticks Tick Borne Dis. 7, 405-414. doi: 10.1016/j.ttbdis.2015.12.017

Kim, T. K., Tirloni, L., Radulovic, Z., Lewis, L., Bakshi, M., Hill, C., et al. (2015). Conserved Amblyomma americanum tick Serpin19, an inhibitor of blood clotting factors $\mathrm{Xa}$ and $\mathrm{XIa}$, trypsin and plasmin, has antihaemostatic functions. Int. J. Parasitol. 45, 613-627. doi: 10.1016/j.ijpara.2015. 03.009

Klingler, J., and Friedrich, T. (1997). Site-specific interaction of thrombin and inhibitors observed by fluorescence correlation spectroscopy. Biophys. J. 73, 2195. doi: 10.1016/S0006-3495(97)78251-1

Koh, C. Y., Kazimirova, M., Trimnell, A., Takac, P., Labuda, M., Nuttall, P. A., et al. (2007). Variegin, a novel fast and tight binding thrombin inhibitor from the tropical bont tick. J. Biol. Chem. 282, 29101-29113. doi: 10.1074/jbc.M705600200

Kopacek, P., Hajdusek, O., Buresova, V., and Daffre, S. (2010). Tick innate immunity. Adv. Exp. Med. Biol. 708, 137-162. doi: 10.1007/ 978-1-4419-8059-5_8

Kopacek, P., Weise, C., Saravanan, T., Vitova, K., and Grubhoffer, L. (2000). Characterization of an alpha-macroglobulin-like glycoprotein isolated from the plasma of the soft tick Ornithodoros moubata. Eur. J. Biochem. 267, 465-475. doi: 10.1046/j.1432-1327.2000.01020.x

Kotal, J., Langhansova, H., Lieskovska, J., Andersen, J. F., Francischetti, I. M., Chavakis, T., et al. (2015). Modulation of host immunity by tick saliva. J. Proteomics 128, 58-68. doi: 10.1016/j.jprot.2015.07.005

Kotsyfakis, M., Kopacek, P., Franta, Z., Pedra, J. H., and Ribeiro, J. M. (2015). Deep sequencing analysis of the Ixodes ricinus haemocytome. PLoS Negl. Trop. Dis. 9:e0003754. doi: 10.1371/journal.pntd.0003754

Krowarsch, D., Cierpicki, T., Jelen, F., and Otlewski, J. (2003). Canonical protein inhibitors of serine proteases. Cell. Mol. Life Sci. 60, 2427-2444. doi: 10.1007/s00018-003-3120-x

Kunitz, M. (1945). Crystallization of a trypsin inhibitor from soybean. Science 101, 668-669. doi: 10.1126/science.101.2635.668

Lai, R., Takeuchi, H., Jonczy, J., Rees, H. H., and Turner, P. C. (2004). A thrombin inhibitor from the ixodid tick, Amblyomma hebraeum. Gene 342, 243-249. doi: 10.1016/j.gene.2004.07.012

Lang, F., Föller, M., Lang, K. S., Lang, P. A., Ritter, M., Gulbins, E., et al. (2005). Ion channels in cell proliferation and apoptotic cell death. J. Membr. Biol. 205, 147-157. doi: 10.1007/s00232-005-0780-5
Larsson, L. J., and Bjork, I. (1984). Kinetics of appearance of sulfhydryl groups in alpha 2-macroglobulin on reaction of the inhibitor with amines. Biochemistry 23, 2802-2807. doi: 10.1021/bi00307a041

Laskowski, M. Jr., and Kato, I. (1980). Protein inhibitors of proteinases. Annu. Rev. Biochem. 49, 593-626. doi: 10.1146/annurev.bi.49.070180.003113

Laskowski, M., and Qasim, M. A. (2000). What can the structures of enzymeinhibitor complexes tell us about the structures of enzyme substrate complexes? Biochim. Biophys. Acta 1477, 324-337. doi: 10.1016/S0167-4838(99)00284-8

Law, R. H., Zhang, Q., McGowan, S., Buckle, A. M., Silverman, G. A., Wong, W., et al. (2006). An overview of the serpin superfamily. Genome Biol. 7:216. doi: 10.1186/gb-2006-7-5-216

Leboulle, G., Crippa, M., Decrem, Y., Mejri, N., Brossard, M., Bollen, A., et al. (2002a). Characterization of a novel salivary immunosuppressive protein from Ixodes ricinus ticks. J. Biol. Chem. 277, 10083-10089. doi: 10.1074/jbc.M111391200

Leboulle, G., Rochez, C., Louahed, J., Ruti, B., Brossard, M., Bollen, A., et al. (2002b). Isolation of Ixodes ricinus salivary gland mRNA encoding factors induced during blood feeding. Am. J. Trop. Med. Hyg. 66, 225-233. doi: 10.4269/ajtmh.2002.66.225

Leger, R. J. S., Charnley, A. K., and Cooper, R. M. (1987). Characterization of cuticle-degrading proteases produced by the entomopathogen Metarhizium anisopliae. Arch. Biochem. Biophys. 253, 221-232. doi: 10.1016/0003-9861(87)90655-2

Liao, M., Zhou, J., Gong, H., Boldbaatar, D., Shirafuji, R., Battur, B., et al. (2009). Hemalin, a thrombin inhibitor isolated from a midgut cDNA library from the hard tick Haemaphysalis longicornis. J. Insect Physiol. 55, 165-174. doi: 10.1016/j.jinsphys.2008.11.004

Lima, C. A., Torquato, R. J. S., Sasaki, S. D., Justo, G. Z., and Tanaka, A. S. (2010). Biochemical characterization of a Kunitz-type inhibitor similar to dendrotoxins produced by Rhipicephalus (Boophilus) microplus (Acari: Ixodidae) hemocytes. Vet. Parasitol. 167, 279-287. doi: 10.1016/j.vetpar.2009.09.030

Limo, M. K., Voigt, W. P., Tumbo-Oeri, A. G., Njogu, R. M., and Ole-MoiYoi, O. K. (1991). Purification and characterization of an anticoagulant from the salivary glands of the ixodid tick Rhipicephalus appendiculatus. Exp. Parasitol. 72, 418-429. doi: 10.1016/0014-4894(91)90088-E

Liu, X. Y., and Bonnet, S. I. (2014). Hard tick factors implicated in pathogen transmission. PLoS Negl. Trop. Dis. 8:e2566. doi: 10.1371/journal.pntd.0002566

Liu, X. Y., de la Fuente, J., Cote, M., Galindo, R. C., Moutailler, S., VayssierTaussat, M., et al. (2014). IrSPI, a tick serine protease inhibitor involved in tick feeding and Bartonella henselae infection. PLoS Negl. Trop. Dis. 8:e2993. doi: 10.1371/journal.pntd.0002993

Macedo-Ribeiro, S., Almeida, C., Calisto, B. M., Friedrich, T., Mentele, R., Stürzebecher, J., et al. (2008). Isolation, cloning and structural characterisation of Boophilin, a multifunctional Kunitz-type proteinase inhibitor from the cattle tick. PLoS ONE 3:e1624. doi: 10.1371/journal.pone.0001624

Madden, R. D., Sauer, J. R., and Dillwith, J. W. (2004). A proteomics approach to characterizing tick salivary secretions. Exp. Appl. Acarol. 32, 77-87. doi: 10.1023/B:APPA.0000018316.80224.54

Mans, B. J., Andersen, J. F., Schwan, T. G., and Ribeiro, J. M. C. (2008). Characterization of anti-hemostatic factors in the argasid, Argas monolakensis: implications for the evolution of blood-feeding in the soft tick family. Insect Biochem. Mol. Biol. 38, 22-41. doi: 10.1016/j.ibmb.2007.09.002

Mans, B. J., Louw, A. I., and Neitz, A. W. H. (2002). Amino acid sequence and structure modeling of savignin, a thrombin inhibitor from the tick, Ornithodoros savignyi. Insect Biochem. Mol. Biol. 32, 821-828. doi: 10.1016/S0965-1748(01)00169-2

Mast, A. E., and Broze, G. J. Jr. (1996). Physiological concentrations of tissue factor pathway inhibitor do not inhibit prothrombinase. Blood 87, 1845-1850.

Metzker, M. L. (2010). Sequencing technologies - the next generation. Nat. Rev. Genet. 11, 31-46. doi: 10.1038/nrg2626

Miyoshi, T., Tsuji, N., Islam, M. K., Alim, M. A., Hatta, T., Yamaji, K., et al. (2010). A Kunitz-type proteinase inhibitor from the midgut of the Ixodid tick, Haemaphysalis longicornis, and its endogenous target serine proteinase. Mol. Biochem. Parasitol. 170, 112-115. doi: 10.1016/j.molbiopara.2009.12.005

Miyoshi, T., Tsuji, N., Khyrul Islam, M., Huang, X., Motobu, M., Abdul Alim, M., et al. (2007). Molecular and reverse genetic characterization of serine proteinase-induced hemolysis in the midgut of the ixodid tick Haemaphysalis longicornis. J. Insect Physiol. 53, 195-203. doi: 10.1016/j.jinsphys.2006.12.001 
Monteiro, R. Q. (2005). Targeting exosites on blood coagulation proteases. Anais Acad. Brasil. Ciênc. 77, 275-280. doi: 10.1590/S0001-37652005000200007

Monteiro, R. Q., Rezaie, A. R., Ribeiro, J. M. C., and Francischetti, I. M. B. (2005). Ixolaris: a factor Xa heparin-binding exosite inhibitor. Biochem. J. 387, 871-877. doi: 10.1042/BJ20041738

Morais, K. L. P., Pacheco, M. T. F., Berra, C. M., Bosch, R. V., Sciani, J. M., Chammas, R., et al. (2016). Amblyomin-X induces ER stress, mitochondrial dysfunction, and caspase activation in human melanoma and pancreatic tumor cell. Mol. Cell. Biochem. 415, 119-131. doi: 10.1007/s11010-016-2683-4

Motoyashiki, T., Tu, A. T., Azimov, D. A., and Ibragim, K. (2003). Isolation of anticoagulant from the venom of tick, Boophilus calcaratus, from Uzbekistan. Thromb. Res. 110, 235-241. doi: 10.1016/S0049-3848(03)00409-2

Mulenga, A., Khumthong, R., and Blandon, M. A. (2007). Molecular and expression analysis of a family of the Amblyomma americanum tick Lospins. J. Exp. Biol. 210, 3188-3198. doi: 10.1242/jeb.006494

Mulenga, A., Kim, T., and Ibelli, A. M. (2013). Amblyomma americanum tick saliva serine protease inhibitor 6 is a cross-class inhibitor of serine proteases and papain-like cysteine proteases that delays plasma clotting and inhibits platelet aggregation. Insect Mol. Biol. 22, 306-319. doi: 10.1111/imb.12024

Mulenga, A., Misao, O., and Sugimoto, C. (2003a). Three serine proteinases from midguts of the hard tick Rhipicephalus appendiculatus; cDNA cloning and preliminary characterization. Exp. Appl. Acarol. 29, 151-164. doi: 10.1023/A:1024278402288

Mulenga, A., Sugimoto, C., Ingram, G., Ohashi, K., and Misao, O. (2001). Characterization of two cDNAs encoding serine proteinases from the hard tick Haemaphysalis longicornis. Insect Biochem. Mol. Biol. 31, 817-825. doi: 10.1016/S0965-1748(00)00187-9

Mulenga, A., Sugimoto, C., Sako, Y., Ohashi, K., Musoke, A., Shubash, M., et al. (1999). Molecular characterization of a Haemaphysalis longicornis tick salivary gland-associated 29-kilodalton protein and its effect as a vaccine against tick infestation in rabbits. Infect. Immun. 67, 1652-1658.

Mulenga, A., Tsuda, A., Onuma, M., and Sugimoto, C. (2003b). Four serine proteinase inhibitors (serpin) from the brown ear tick, Rhiphicephalus appendiculatus; cDNA cloning and preliminary characterization. Insect Biochem. Mol. Biol. 33, 267-276. doi: 10.1016/S0965-1748(02)00240-0

Munoz, E. M., and Linhardt, R. J. (2004). Heparin-binding domains in vascular biology. Arterioscler. Thromb. Vasc. Biol. 24, 1549-1557. doi: 10.1161/01.ATV.0000137189.22999.3f

Nagata, K. (1996). Hsp47: a collagen-specific molecular chaperone. Trends Biochem. Sci. 21, 22-26. doi: 10.1016/S0968-0004(06)80023-X

Nagata, S. (2000). Apoptotic DNA fragmentation. Exp. Cell Res. 256, 12-18. doi: 10.1006/excr.2000.4834

Nakajima, C., Imamura, S., Konnai, S., Yamada, S., Nishikado, H., Ohashi, K., et al. (2006). A novel gene encoding a thrombin inhibitory protein in a cDNA library from Haemaphysalis longicornis salivary gland. J. Vet. Med. Sci. 68, 447-452. doi: $10.1292 /$ jvms. 68.447

Narasimhan, S., Perez, O., Mootien, S., DePonte, K., Koski, R. A., Fikrig, E., et al. (2013). Characterization of Ixophilin, a thrombin inhibitor from the gut of Ixodes scapularis. PLoS ONE 8:e68012. doi: 10.1371/journal.pone.0068012

Nurden, A. T. (2014). Platelet membrane glycoproteins: a historical review. Semin. Thromb. Hemost. 40, 577-584. doi: 10.1055/s-0034-1383826

Nutt, L. K., Pataer, A., Pahler, J., Fang, B., Roth, J., McConkey, D. J., et al. (2002). Bax and Bak promote apoptosis by modulating endoplasmic reticular and mitochondrial $\mathrm{Ca}^{2+}$ stores. J. Biol. Chem. 277, 9219-9225. doi: 10.1074/jbc.M106817200

Nuttall, P. A., and Labuda, M. (2004). Tick-host interactions: salivaactivated transmission. Parasitology 129(Suppl.), S177-S189. doi: 10.1017/ S0031182004005633

Oleaga, A., Obolo-Mvoulouga, P., Manzano-Roman, R., and Perez-Sanchez, R. (2015). Midgut proteome of an argasid tick, Ornithodoros erraticus: a comparison between unfed and engorged females. Parasit. Vectors 8, 525. doi: 10.1186/s13071-015-1148-z

Paesen, G. C., Adams, P. L., Harlos, K., Nuttall, P. A., and Stuart, D. I. (1999). Tick histamine-binding proteins: isolation, cloning, and three-dimensional structure. Mol. Cell 3, 661-671. doi: 10.1016/S1097-2765(00)80359-7

Paesen, G. C., Siebold, C., Harlos, K., Peacey, M. F., Nuttall, P. A., and Stuart, D. I. (2007). A tick protein with a modified Kunitz fold inhibits human tryptase. J. Mol. Biol. 368, 1172-1186. doi: 10.1016/j.jmb.2007.03.011
Páleníková, J., Lieskovská, J., Langhansová, H., Kotsyfakis, M., Chmelař, J., and Kopecký, J. (2015). Ixodes ricinus salivary serpin IRS-2 affects Th17 differentiation via inhibition of the interleukin-6/STAT-3 signaling pathway. Infect. Immun. 83, 1949-1956. doi: 10.1128/IAI.03065-14

Payne, V., and Kam, P. C. (2004). Mast cell tryptase: a review of its physiology and clinical significance. Anaesthesia 59, 695-703. doi: 10.1111/j.1365-2044.2004.03757.x

Pemberton, P. A., Stein, P. E., Pepys, M. B., Potter, J. M., and Carrell, R. W. (1988). Hormone binding globulins undergo serpin conformational change in inflammation. Nature 336, 257-258. doi: 10.1038/336257a0

Peslova, G., Petrak, J., Kuzelova, K., Hrdy, I., Halada, P., Kuchel, P. W., et al. (2009). Hepcidin, the hormone of iron metabolism, is bound specifically to alpha-2-macroglobulin in blood. Blood 113, 6225-6236. doi: 10.1182/blood-2009-01-201590

Porter, L., Radulovic, Z., Kim, T., Braz, G. R., Da Silva Vaz, I. Jr., and Mulenga, A. (2015). Bioinformatic analyses of male and female Amblyomma americanum tick expressed serine protease inhibitors (serpins). Ticks Tick Borne Dis. 6, 16-30. doi: $10.1016 /$ j.ttbdis.2014.08.002

Prevot, P. P. (2006). Anti-hemostatic effects of a serpin from the saliva of the tick Ixodes ricinus. J. Biol. Chem. 281, 26361-26369. doi: 10.1074/jbc.M604197200

Prevot, P.-P., Beschin, A., Lins, L., Beaufays, J., Grosjean, A., Bruys, L., et al. (2009). Exosites mediate the anti-inflammatory effects of a multifunctional serpin from the saliva of the tick Ixodes ricinus. FEBS J. 276, 3235-3246. doi: 10.1111/j.1742-4658.2009.07038.x

Rachinsky, A., Guerrero, F. D., and Scoles, G. A. (2007). Differential protein expression in ovaries of uninfected and Babesia-infected southern cattle ticks, Rhipicephalus (Boophilus) microplus. Insect Biochem. Mol. Biol. 37, 1291-1308. doi: 10.1016/j.ibmb.2007.08.001

Radulovic, Z. M., Kim, T. K., Porter, L. M., Sze, S. H., Lewis, L., and Mulenga, A. (2014). A $24-48 \mathrm{~h}$ fed Amblyomma americanum tick saliva immuno-proteome. BMC Genomics 15:518. doi: 10.1186/1471-2164-15-518

Rajput, Z. I., Hu, S. H., Chen, W. J., Arijo, A. G., and Xiao, C. W. (2006). Importance of ticks and their chemical and immunological control in livestock. J. Zhejiang Univ. Sci. B 7, 912-921. doi: 10.1631/jzus.2006.B0912

Ram, J. S., Terminiello, L., Bier, M., and Nord, F. F. (1954). On the mechanism of enzyme action. LVII. Interaction between trypsin and ovomucoid. Arch. Biochem. Biophys. 52, 451-463. doi: 10.1016/0003-9861(54)90145-9

Ramamoorthi, N., Narasimhan, S., Pal, U., Bao, F., Yang, X. F., Fish, D., et al. (2005). The Lyme disease agent exploits a tick protein to infect the mammalian host. Nature 436, 573-577. doi: 10.1038/nature03812

Ranasinghe, S., and McManus, D. P. (2013). Structure and function of invertebrate Kunitz serine protease inhibitors. Dev. Comp. Immunol. 39, 219-227. doi: $10.1016 /$ j.dci.2012.10.005

Rawlings, N. D., Tolle, D. P., and Barrett, A. J. (2004). Evolutionary families of peptidase inhibitors. Biochem. J. 378, 705-716. doi: 10.1042/bj20 031825

Ray, C. A., Black, R. A., Kronheim, S. R., Greenstreet, T. A., Sleath, P. R., Salvesen, G. S., et al. (1992). Viral inhibition of inflammation: cowpox virus encodes an inhibitor of the interleukin-1 beta converting enzyme. Cell 69, 597-604. doi: 10.1016/0092-8674(92)90223-Y

Ribeiro, J. M. (1995). Blood-feeding arthropods: live syringes or invertebrate pharmacologists? Infect. Agents Dis. 4, 143-152.

Ribeiro, J. M., Alarcon-Chaidez, F., Francischetti, I. M., Mans, B. J., Mather, T. N., Valenzuela, J. G., et al. (2006). An annotated catalog of salivary gland transcripts from Ixodes scapularis ticks. Insect Biochem. Mol. Biol. 36, 111-129. doi: 10.1016/j.ibmb.2005.11.005

Ribeiro, J. M., Makoul, G. T., Levine, J., Robinson, D. R., and Spielman, A. (1985). Antihemostatic, antiinflammatory, and immunosuppressive properties of the saliva of a tick, Ixodes dammini. J. Exp. Med. 161, 332-344. doi: 10.1084/jem.161.2.332

Ricci, C. G., Pinto, A. F. M., Berger, M., and Termignoni, C. (2007). A thrombin inhibitor from the gut of Boophilus microplus ticks. Exp. Appl. Acarol. 42, 291-300. doi: 10.1007/s10493-007-9097-7

Rimphanitchayakit, V., and Tassanakajon, A. (2010). Structure and function of invertebrate Kazal-type serine proteinase inhibitors. Dev. Comp. Immunol. 34, 377-386. doi: 10.1016/j.dci.2009.12.004

Rodriguez-Valle, M., Vance, M., Moolhuijzen, P. M., Tao, X., and Lew-Tabor, A. E. (2012). Differential recognition by tick-resistant cattle of the recombinantly 
expressed Rhipicephalus microplus serine protease inhibitor-3 (RMS-3). Ticks Tick Borne Dis. 3, 159-169. doi: 10.1016/j.ttbdis.2012.03.002

Rodriguez-Valle, M., Xu, T., Kurscheid, S., and Lew-Tabor, A. E. (2015). Rhipicephalus microplus serine protease inhibitor family: annotation, expression and functional characterisation assessment. Parasit. Vectors 8, 7. doi: 10.1186/s13071-014-0605-4

Rosario-Cruz, R., Almazan, C., Miller, R. J., Dominguez-Garcia, D. I., HernandezOrtiz, R., and de la Fuente, J. (2009). Genetic basis and impact of tick acaricide resistance. Front. Biosci. (Landmark Ed.) 14, 2657-2665. doi: 10.2741/3403

Sabbatini (1899). Fermento anticoagulente del l'Ixodes ricinus. Ach. Ital. Biol. 31, 37-53.

Sakai, K., Long, S. D., Pettit, D. A. D., Cabral, G. A., and Schwartz, L. B. (1996). Expression and purification of recombinant human tryptase in a baculovirus system. Protein Expr. Purif. 7, 67-73. doi: 10.1006/prep.1996.0010

Sant'Anna Azzolini, S., Sasaki, S. D., Torquato, R. J., Andreotti, R., Andreotti, E., and Tanaka, A. S. (2003). Rhipicephalus sanguineus trypsin inhibitors present in the tick larvae: isolation, characterization, and partial primary structure determination. Arch. Biochem. Biophys. 417, 176-182. doi: 10.1016/S0003-9861(03)00344-8

Santos, I. K., Valenzuela, J. G., Ribeiro, J. M., de Castro, M., Costa, J. N., Costa, A. M., et al. (2004). Gene discovery in Boophilus microplus, the cattle tick: the transcriptomes of ovaries, salivary glands, and hemocytes. Ann. N. Y. Acad. Sci. 1026, 242-246. doi: 10.1196/annals.1307.037

Saravanan, T., Weise, C., Sojka, D., and Kopácek, P. (2003). Molecular cloning, structure and bait region splice variants of alpha2-macroglobulin from the soft tick Ornithodoros moubata. Insect Biochem. Mol. Biol. 33, 841-851. doi: 10.1016/S0965-1748(03)00083-3

Sasaki, S. D., Azzolini, S. S., Hirata, I. Y., Andreotti, R., and Tanaka, A. S. (2004). Boophilus microplus tick larvae, a rich source of Kunitz-type serine proteinase inhibitors. Biochimie 86, 643-649. doi: 10.1016/j.biochi.2004.09.010

Sasaki, S. D., de Lima, C. A., Lovato, D. V., Juliano, M. A., Torquato, R. J. S., and Tanaka, A. S. (2008). BmSI-7, a novel subtilisin inhibitor from Boophilus microplus, with activity toward Pr1 proteases from the fungus Metarhizium anisopliae. Exp. Parasitol. 118, 214-220. doi: 10.1016/j.exppara.2007.08.003

Sasaki, S. D., and Tanaka, A. S. (2008). rBmTI-6, a Kunitz-BPTI domain protease inhibitor from the tick Boophilus microplus, its cloning, expression and biochemical characterization. Vet. Parasitol. 155, 133-141. doi: 10.1016/j.vetpar.2008.03.031

Schlott, B., Wohnert, J., Icke, C., Hartmann, M., Ramachandran, R., Guhrs, K. H., et al. (2002). Interaction of Kazal-type inhibitor domains with serine proteinases: biochemical and structural studies. J. Mol. Biol. 318, 533-546. doi: 10.1016/S0022-2836(02)00014-1

Schwarz, A., Tenzer, S., Hackenberg, M., Erhart, J., Gerhold-Ay, A., Mazur, J., et al. (2014). A systems level analysis reveals transcriptomic and proteomic complexity in Ixodes ricinus midgut and salivary glands during early attachment and feeding. Mol. Cell. Proteomics 13, 2725-2735. doi: $10.1074 /$ mcp.M114.039289

Soares, T. S., Oliveira, F., Torquato, R. J. S., Sasaki, S. D., Araujo, M. S., Paschoalin, T., et al. (2016). BmTI-A, a Kunitz-type inhibitor from Rhipicephalus microplus able to interfere in vessel formation. Vet. Parasitol. 219, 44-52. doi: 10.1016/j.vetpar.2016.01.021

Soares, T. S., Watanabe, R. M. O., Tanaka-Azevedo, A. M., Torquato, R. J. S., Lu, S., Figueiredo, A. C., et al. (2012). Expression and functional characterization of boophilin, a thrombin inhibitor from Rhipicephalus (Boophilus) microplus midgut. Vet. Parasitol. 187, 521-528. doi: 10.1016/j.vetpar.2012.01.027

Somprasong, N., Rimphanitchayakit, V., and Tassanakajon, A. (2006). A fivedomain Kazal-type serine proteinase inhibitor from black tiger shrimp Penaeus monodon and its inhibitory activities. Dev. Comp. Immun. 30, 998-1008. doi: 10.1016/j.dci.2006.01.004

Sonenshine, D., and Anderson, J. (2014). "Mouthparts and digestive system," in Biology of Ticks, 2 nd Edn., eds. D. E. Sonenshine and R. Michael Roe (New York, NY: Oxford University Press), 122-162.

Sottrup-Jensen, L. (1989). Alpha-macroglobulins: structure, shape, and mechanism of proteinase complex formation. J. Biol. Chem. 264, 11539-11542.

Sottrup-Jensen, L., Stepanik, T. M., Kristensen, T., Lonblad, P. B., Jones, C. M., Wierzbicki, D. M., et al. (1985). Common evolutionary origin of alpha 2macroglobulin and complement components C3 and C4. Proc. Natl. Acad. Sci. U.S.A. 82, 9-13. doi: 10.1073/pnas.82.1.9
Starkey, P. M., and Barrett, A. J. (1982). Evolution of alpha 2-macroglobulin. The demonstration in a variety of vertebrate species of a protein resembling human alpha 2-macroglobulin. Biochem. J. 205, 91-95. doi: 10.1042/bj20 50091

Stopforth, E., Neitz, A. W., and Gaspar, A. R. (2010). A proteomics approach for the analysis of hemolymph proteins involved in the immediate defense response of the soft tick, Ornithodoros savignyi, when challenged with Candida albicans. Exp. Appl. Acarol. 51, 309-325. doi: 10.1007/s10493-010-9338-z

Sugino, M., Imamura, S., Mulenga, A., Nakajima, M., Tsuda, A., Ohashi, K., et al. (2003). A serine proteinase inhibitor (serpin) from ixodid tick Haemaphysalis longicornis; cloning and preliminary assessment of its suitability as a candidate for a tick vaccine. Vaccine 21, 2844-2851. doi: 10.1016/S0264-410X(03) 00167-1

Syrovets, T., Lunov, O., and Simmet, T. (2012). Plasmin as a proinflammatory cell activator. J. Leukoc. Biol. 92, 509-519. doi: 10.1189/jlb.0212056

Tanaka, A. S., Andreotti, R., Gomes, A., Torquato, R. J., Sampaio, M. U., and Sampaio, C. A. (1999). A double headed serine proteinase inhibitor-human plasma kallikrein and elastase inhibitor-from Boophilus microplus larvae. Immunopharmacology 45, 171-177. doi: 10.1016/S0162-3109(99)00074-0

Tatchell, R. J. (1969). Host-parasite interactions and the feeding of blood-sucking arthropods. Parasitology 59, 93-104. doi: 10.1017/S0031182000069857

Tirloni, L., Islam, M. S., Kim, T. K., Diedrich, J. K., Yates, J. R. III, Pinto, A. F., et al. (2015). Saliva from nymph and adult females of Haemaphysalis longicornis: a proteomic study. Parasit. Vectors 8, 338. doi: 10.1186/s13071-015-0918-y

Tirloni, L., Reck, J., Terra, R. M., Martins, J. R., Mulenga, A., Sherman, N. E., et al. (2014a). Proteomic analysis of cattle tick Rhipicephalus (Boophilus) microplus saliva: a comparison between partially and fully engorged females. PLoS ONE 9:e94831. doi: 10.1371/journal.pone.0094831

Tirloni, L., Seixas, A., Mulenga, A., Vaz Ida, S. Jr., and Termignoni, C. (2014b). A family of serine protease inhibitors (serpins) in the cattle tick Rhipicephalus (Boophilus) microplus. Exp. Parasitol. 137, 25-34. doi: 10.1016/j.exppara.2013.12.001

Toyomane, K., Konnai, S., Niwa, A., Githaka, N., Isezaki, M., Yamada, S., et al. (2016). Identification and the preliminary in vitro characterization of IRIS homologue from salivary glands of Ixodes persulcatus Schulze. Ticks Tick Borne Dis. 7, 119-125. doi: 10.1016/j.ttbdis.2015.09.006

Tsuda, A., Mulenga, A., Sugimoto, C., Nakajima, M., Ohashi, K., and Onuma, M. (2001). cDNA cloning, characterization and vaccine effect analysis of Haemaphysalis longicornis tick saliva proteins. Vaccine 19, 4287-4296. doi: 10.1016/S0264-410X(01)00148-7

Tufail, M., and Takeda, M. (2009). Insect vitellogenin/lipophorin receptors: molecular structures, role in oogenesis, and regulatory mechanisms. J. Insect Physiol. 55, 87-103. doi: 10.1016/j.jinsphys.2008.11.007

Valdés, J. J., Schwarz, A., Cabeza de Vaca, I., Calvo, E., Pedra, J. H. F., Guallar, V., et al. (2013). Tryptogalinin is a tick kunitz serine protease inhibitor with a unique intrinsic disorder. PLOS ONE 8:e62562. doi: 10.1371/journal.pone.0062562

van de Locht, A., Stubbs, M. T., Bode, W., Friedrich, T., Bollschweiler, C., Hoffken, W., et al. (1996). The ornithodorin-thrombin crystal structure, a key to the TAP enigma? EMBO J. 15, 6011-6017.

Wada, Y., Yoshida, K., Tsutani, Y., Shigematsu, H., Oeda, M., Sanada, Y., et al. (2007). Neutrophil elastase induces cell proliferation and migration by the release of TGF- $\alpha$, PDGF and VEGF in esophageal cell lines. Oncol. Rep. 17, 161-167. doi: 10.3892/or.17.1.161

Walker, D. H., Tidwell, R. R., Rector, T. M., and Geratz, J. D. (1984). Effect of synthetic protease inhibitors of the amidine type on cell injury by Rickettsia rickettsii. Antimicrob. Agents Chemother. 25, 582-585. doi: 10.1128/AAC.25.5.582

Wang, Z. H., Zhao, X. F., and Wang, J. X. (2009). Characterization, kinetics, and possible function of Kazal-type proteinase inhibitors of Chinese white shrimp, Fenneropenaeus chinensis. Fish Shellfish Immunol. 26, 885-897. doi: 10.1016/j.fsi.2009.03.024

Waxman, L., Smith, D. E., Arcuri, K. E., and Vlasuk, G. P. (1990). Tick anticoagulant peptide (TAP) is a novel inhibitor of blood coagulation factor Xa. Science 248, 593-596. doi: 10.1126/science. 2333510

Wikel, S. (2013). Ticks and tick-borne pathogens at the cutaneous interface: host defenses, tick countermeasures, and a suitable environment for pathogen establishment. Front. Microbiol. 4:337. doi: 10.3389/fmicb.2013.00337 
Willadsen, P., and Riding, G. A. (1980). On the biological role of a proteolyticenzyme inhibitor from the ectoparasitic tick Boophilus microplus. Biochem. J. 189, 295-303. doi: 10.1042/bj1890295

Xu, T., Lew-Tabor, A., and Rodriguez-Valle, M. (2016). Effective inhibition of thrombin by Rhipicephalus microplus serpin-15 (RmS-15) obtained in the yeast Pichia pastoris. Ticks Tick Borne Dis. 7, 180-187. doi: 10.1016/j.ttbdis.2015.09.007

Yu, Y., Cao, J., Zhou, Y., Zhang, H., and Zhou, J. (2013). Isolation and characterization of two novel serpins from the tick Rhipicephalus haemaphysaloides. Ticks Tick Borne Dis. 4, 297-303. doi: 10.1016/j.ttbdis.2013.02.001

Zarbock, A., Polanowska-Grabowska, R. K., and Ley, K. (2007). Plateletneutrophil-interactions: linking hemostasis and inflammation. Blood Rev. 21, 99-111. doi: 10.1016/j.blre.2006.06.001

Zhou, J., Liao, M., Hatta, T., Tanaka, M., Xuan, X., and Fujisaki, K. (2006). Identification of a follistatin-related protein from the tick Haemaphysalis longicornis and its effect on tick oviposition. Gene 372, 191-198. doi: 10.1016/j.gene.2005.12.020
Zhu, K., Bowman, A. S., Brigham, D. L., Essenberg, R. C., Dillwith, J. W., and Sauer, J. R. (1997). Isolation and characterization of americanin, a specific inhibitor of thrombin, from the salivary glands of the lone star tick Amblyomma americanum (L.). Exp. Parasitol. 87, 30-38. doi: 10.1006/expr.1997.4175

Zou, Z., Anisowicz, A., Hendrix, M. J., Thor, A., Neveu, M., Sheng, S., et al. (1994). Maspin, a serpin with tumor-suppressing activity in human mammary epithelial cells. Science 263, 526-529. doi: 10.1126/science.8290962

Conflict of Interest Statement: The authors declare that the research was conducted in the absence of any commercial or financial relationships that could be construed as a potential conflict of interest.

Copyright (c) 2017 Blisnick, Foulon and Bonnet. This is an open-access article distributed under the terms of the Creative Commons Attribution License (CC BY). The use, distribution or reproduction in other forums is permitted, provided the original author(s) or licensor are credited and that the original publication in this journal is cited, in accordance with accepted academic practice. No use, distribution or reproduction is permitted which does not comply with these terms. 